\title{
الوسائل البديلة ودورها في تغطية اضرار تلوث البيئة بالنفط
}

\author{
نارام ساي قادر ' دلشاد نجات سعيد r

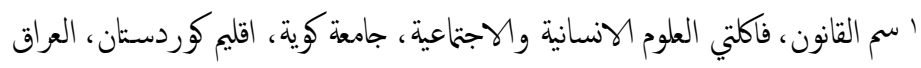

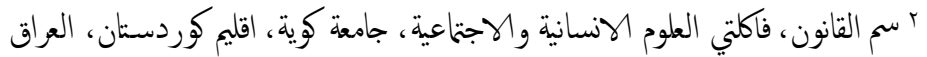

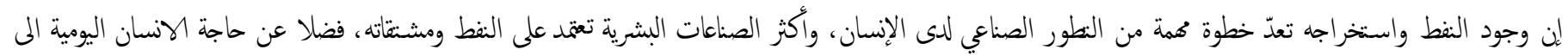

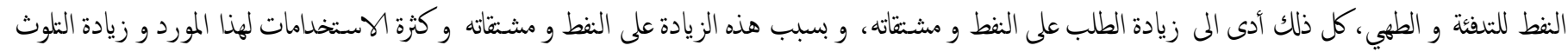

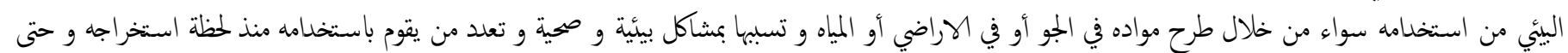

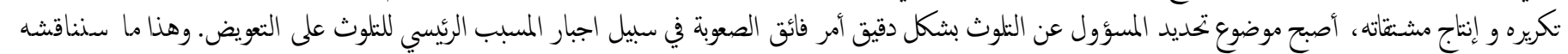

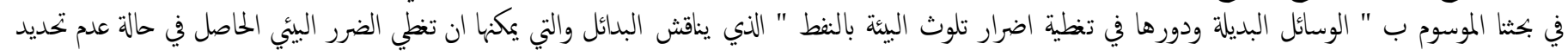

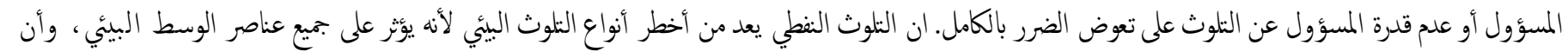

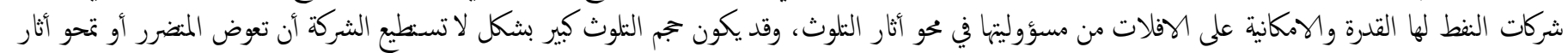

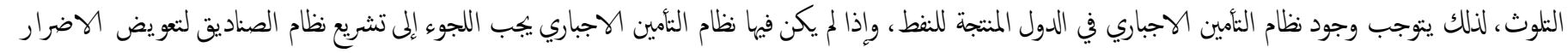

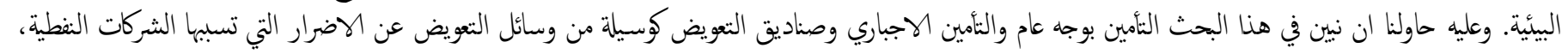

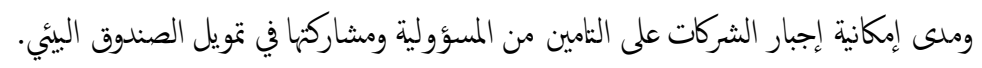

مفاتيح الكلمات: البيئة، التعويضات، الثلوث النفطي، قوانين البيئة، المسؤولية.

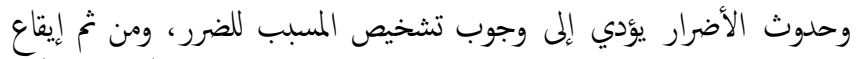

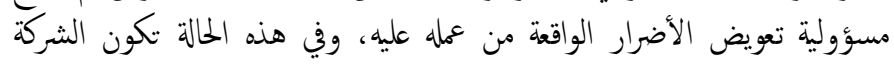

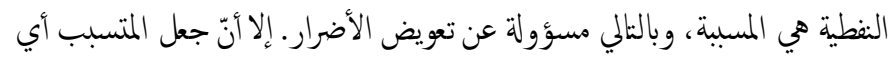

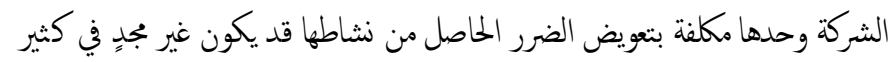

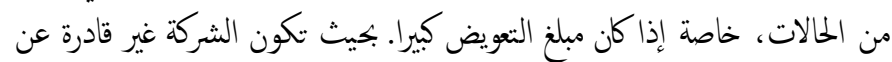

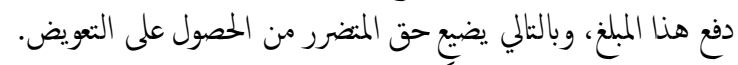

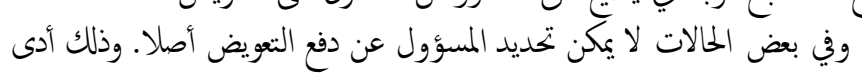

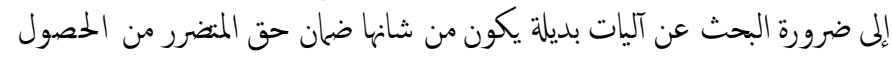

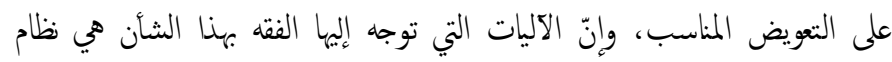

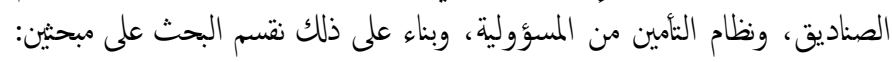

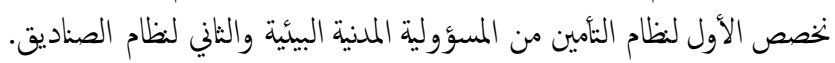

\section{r. التأمين من المسؤولية عن أضرار الثلوث البيتي وطبيعته القانوية}

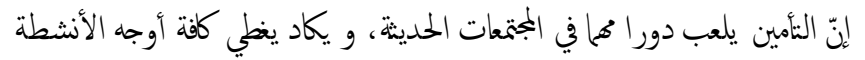

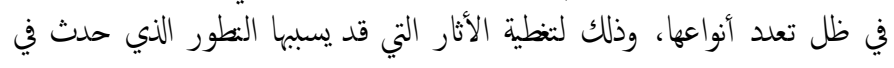

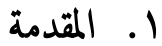

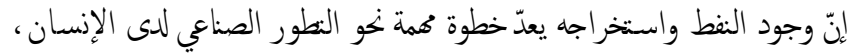

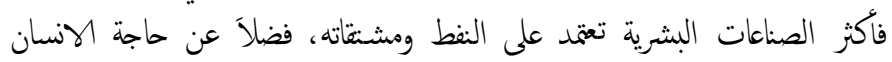

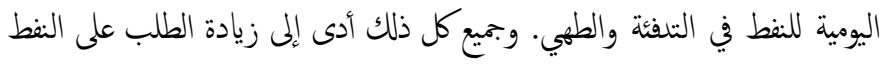

ومشتقانه. وقد زاد اليوم إنتاج النفط لدى الشركات النفطية وذلك باستعال الوسائل الحديثة

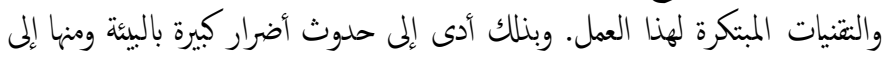
الإنسان. 
وعليه يككن القول بالرغ من اختلاف التعريفات حول التأمين من المسؤولية إن

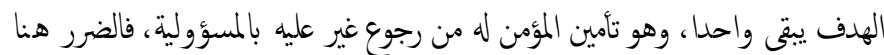

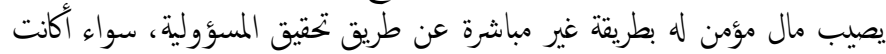
مسؤولية عقدية أح تقصيرية.

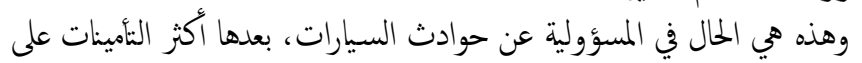

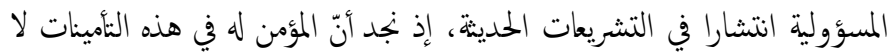

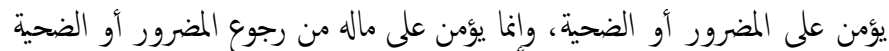

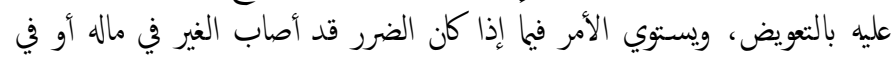
جسده، وعليه فإن التأمين من المسؤولية يركز على أشخاص ثلاثة هم المؤمن والمؤمن

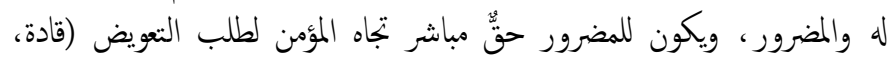
. (119-1MN، r.17

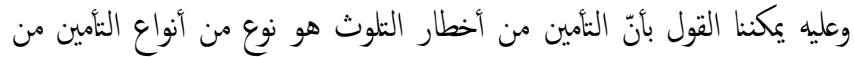

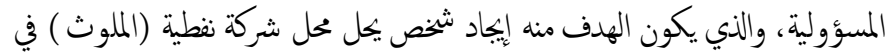

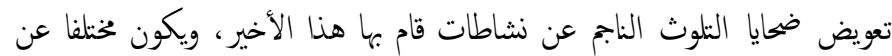

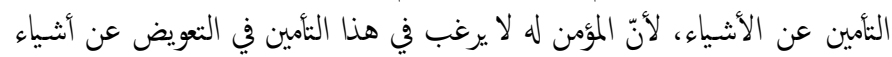

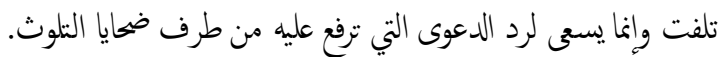

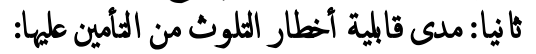

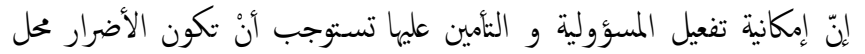

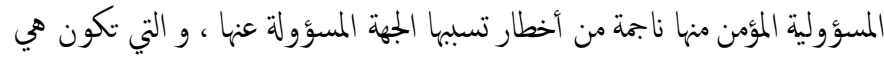

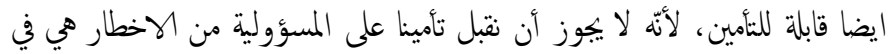

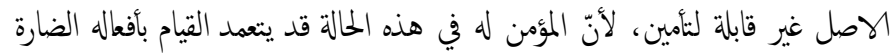

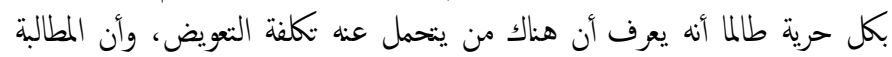

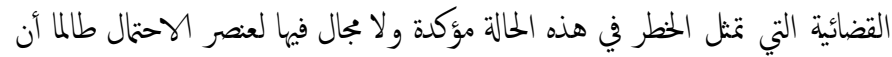

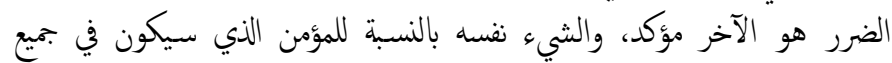

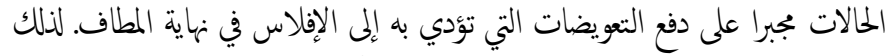

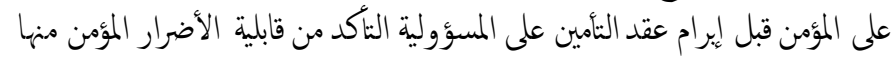

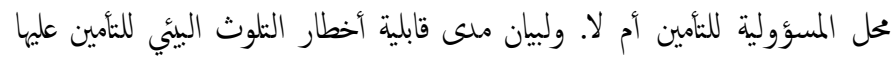

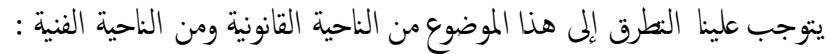

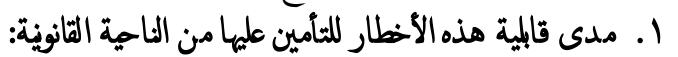

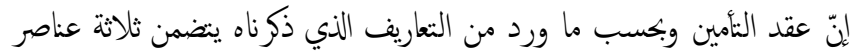

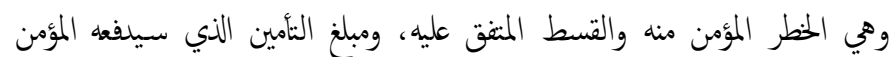

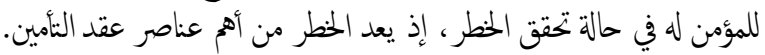

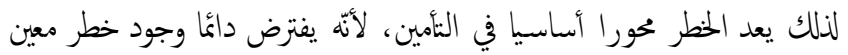

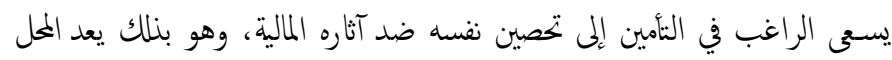

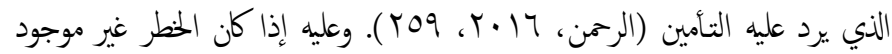

فيكون عقد التأمين باطلاً لتخلف ركن المحل.

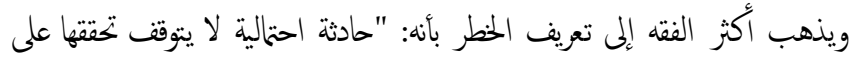

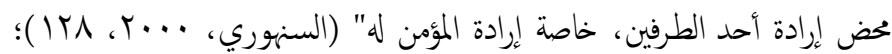

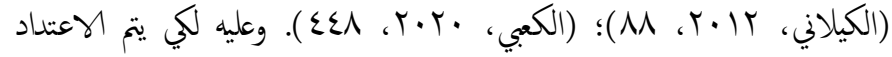

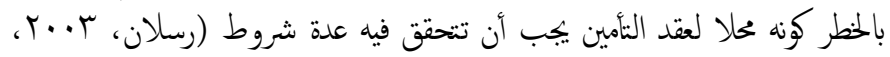

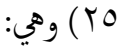

شتى مجالات الحياة، وما يصاحها من خطورة المسؤوليات المرتبطة بها، وظهور مخاطر

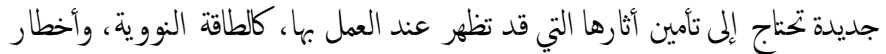

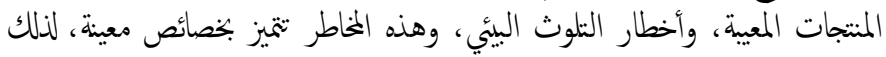

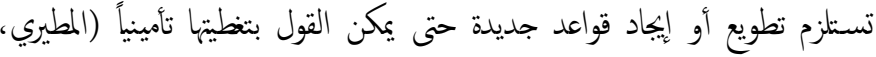

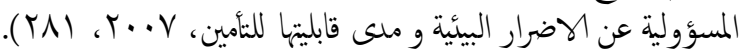

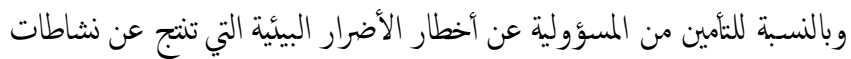

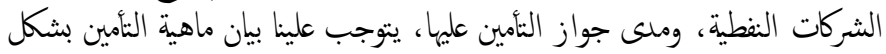

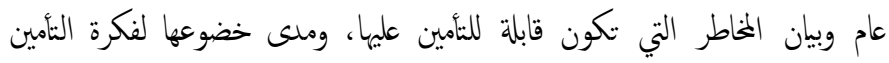

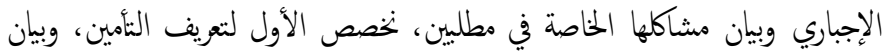

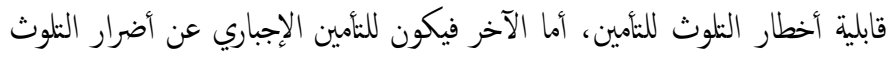
البيئي، والمشكلات الخاصة بخطر التلوث:

\section{r.1 المطلب الأول: تعريف الثأمين ويان قابية أخطار الثلوث للتأمين:}

نططرق في هنا المطلب إلى تعيف التأمين أولاً وثانيا ملى قابلية أخطار الثنوث من الثأمين

أولا: تعريف التأمين: تتمثل فكرة التأمين من المسؤولية بوجود شخص ما يخشى أن

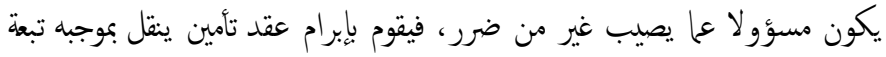

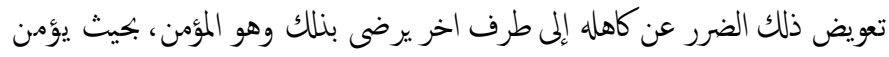

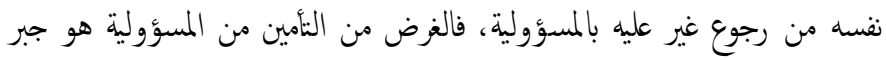

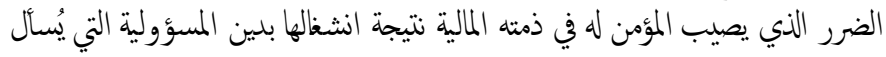

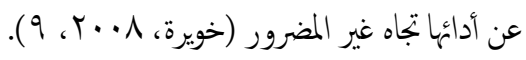

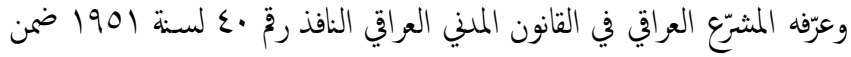

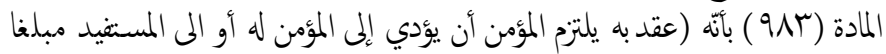

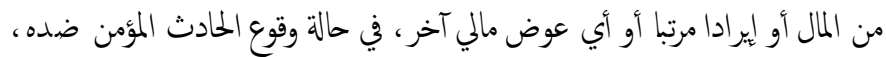

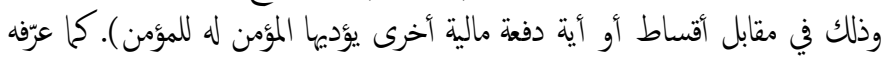

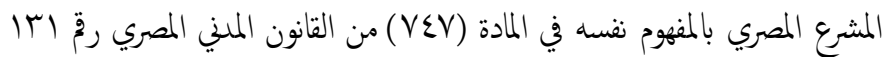

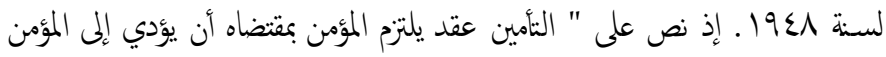

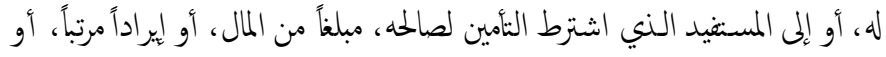

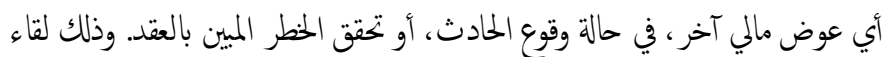

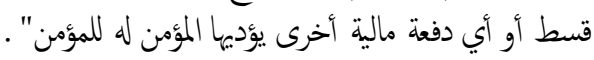

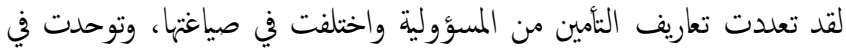

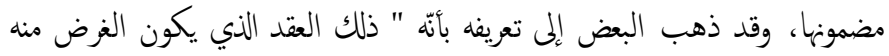

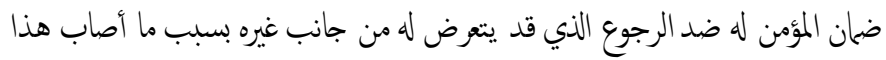

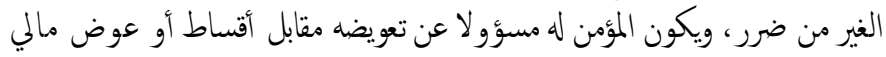

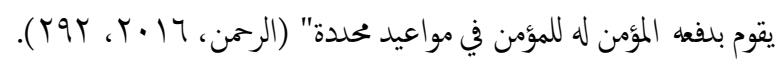

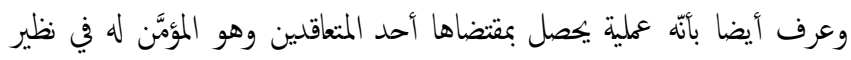

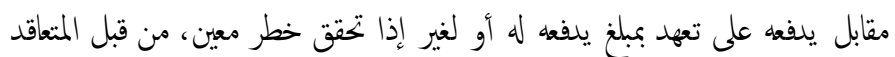

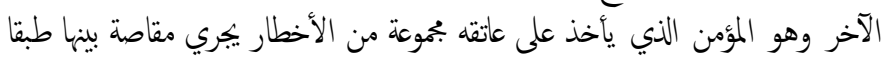

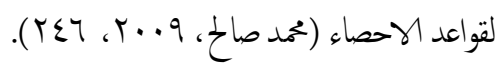

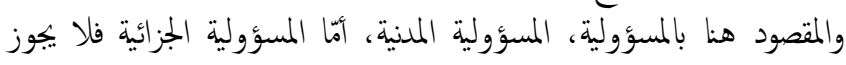

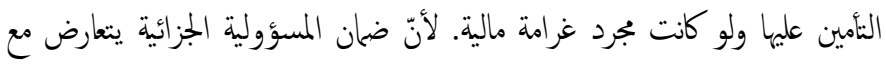

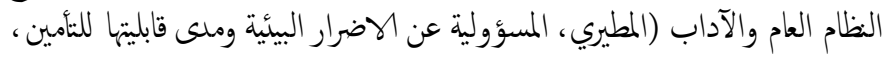

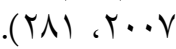




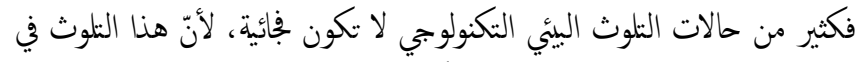

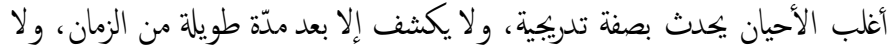

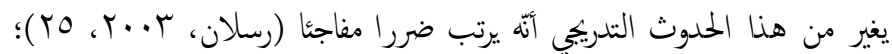

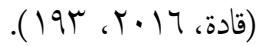

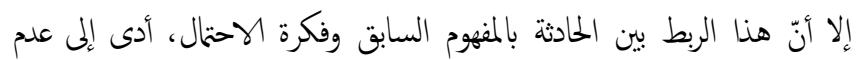

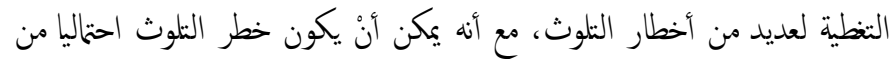

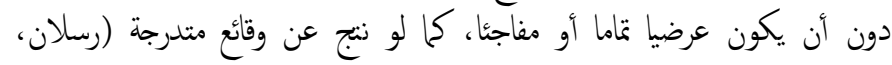

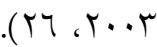

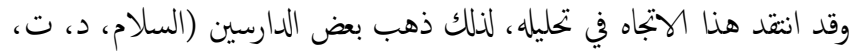

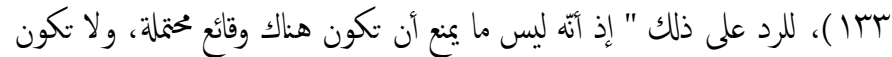

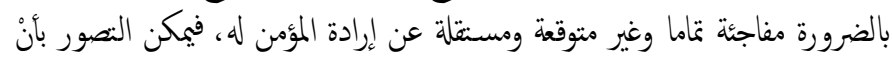

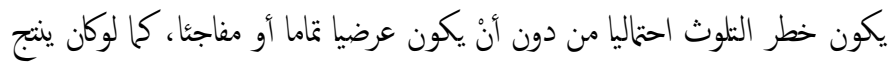
عن وقائع متدرجة." وهنا ما جعل من شركات التأمين الفرنسية أن يظهرون قدرا من المرونة في تحديد

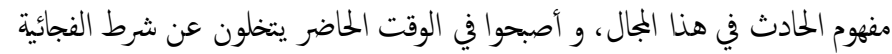

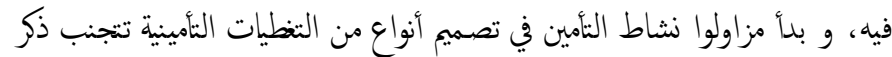

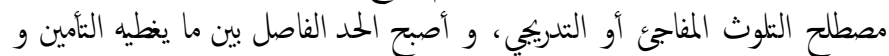

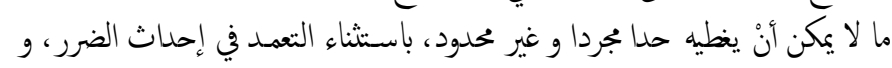

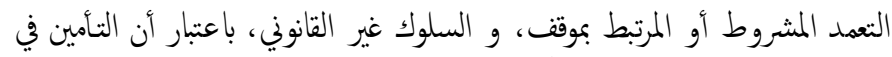

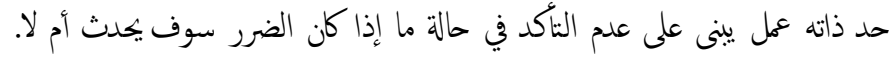

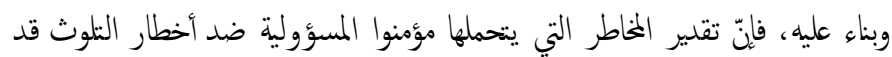

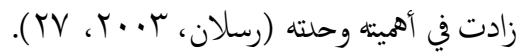

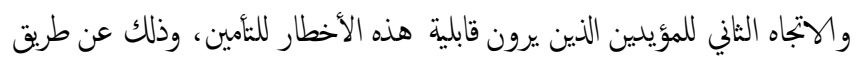

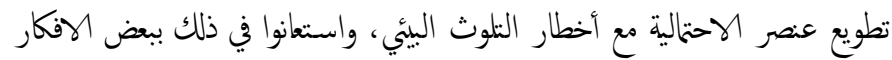

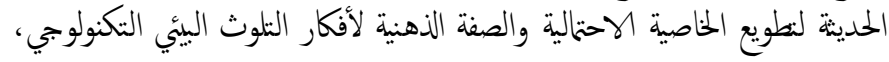

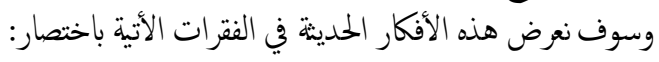

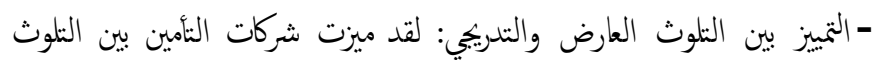

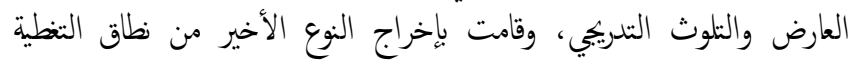

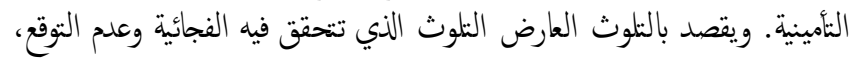

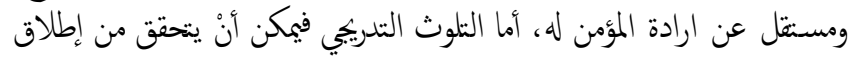

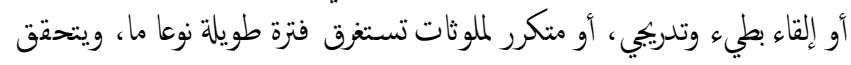

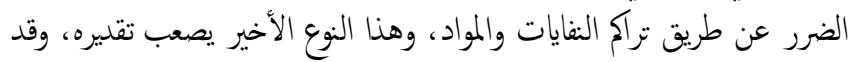

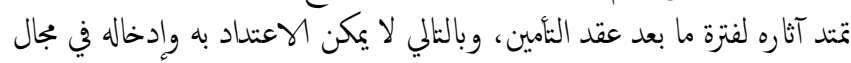

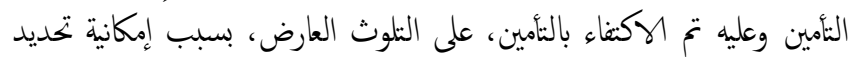

الصفة الفجائية فيه (السلام، د، ت، عَاها ).

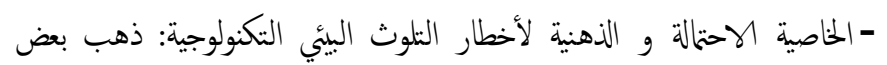

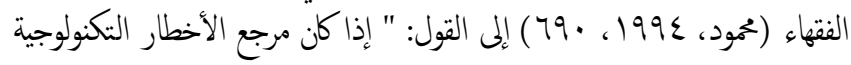

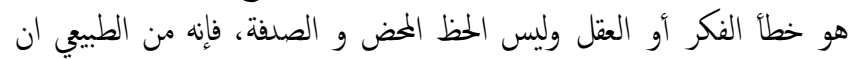

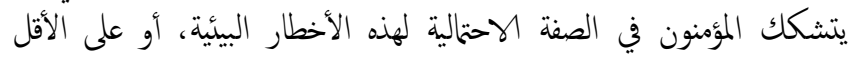

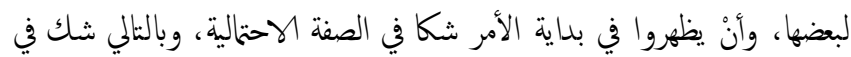

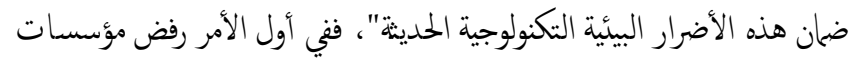

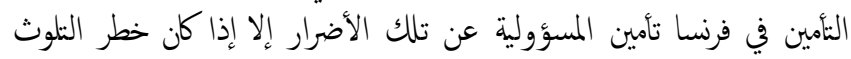

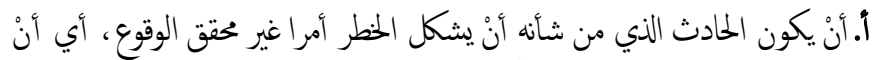

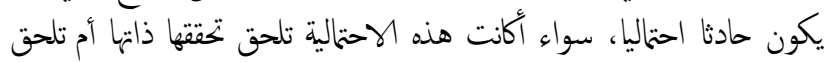

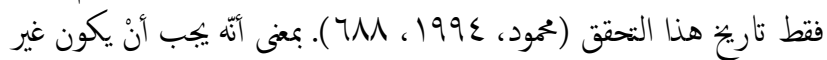

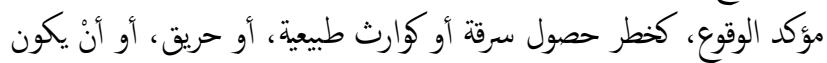

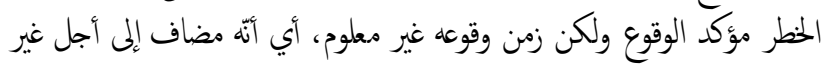

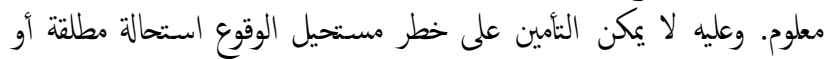

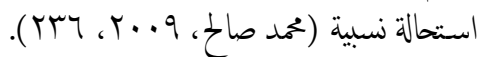

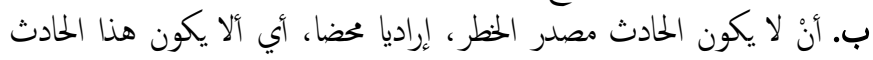

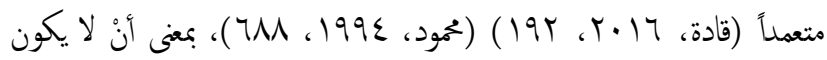

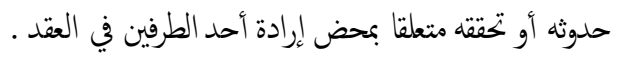

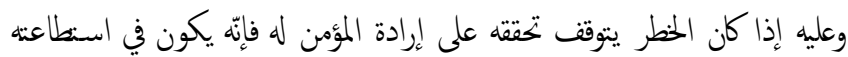

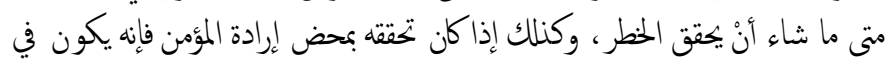

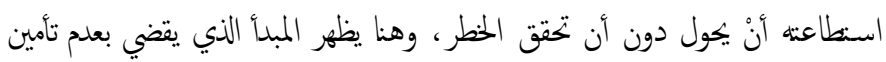

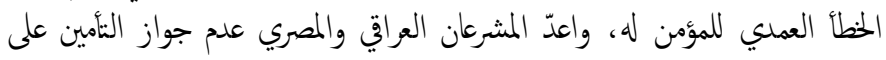

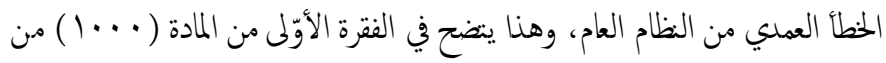

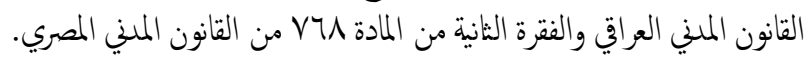

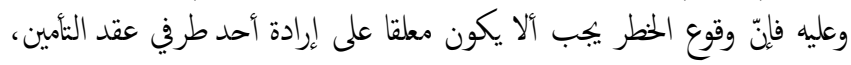

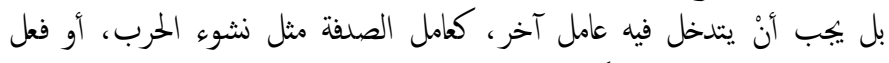

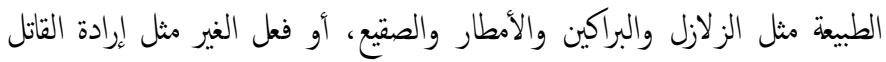

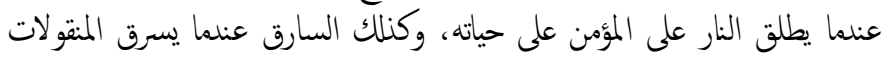

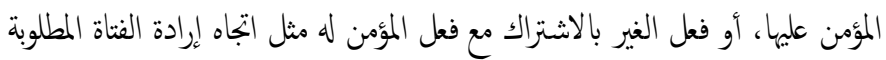

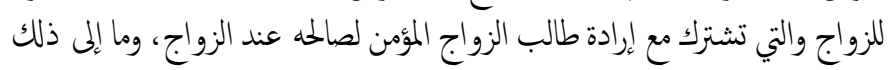

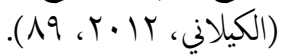
فضلا عن ذلك يجب أنْ يكون الخطر المؤمن عليه مشروعا وغير مخالف للنظام

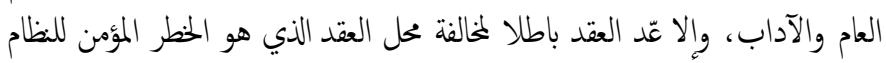

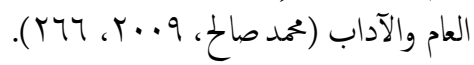

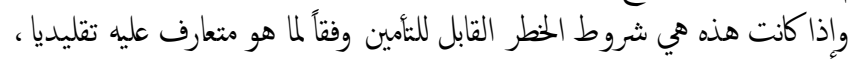

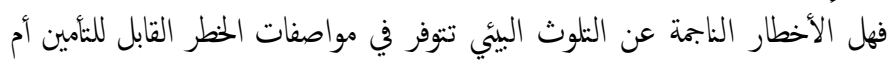

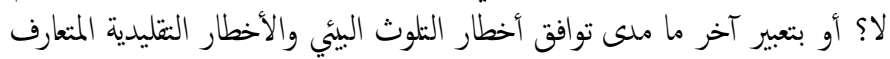

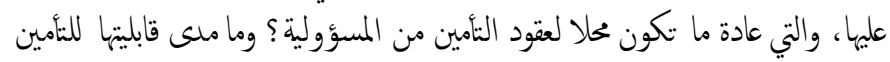

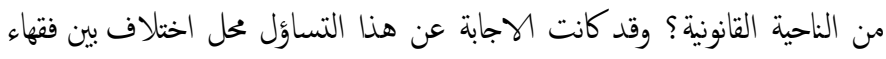
القانون فانتسموا بين مؤيدومعارض الماند التأمين على هذه الأخطار.

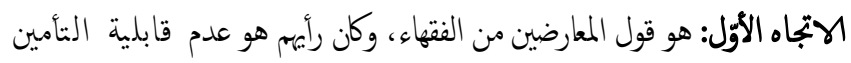

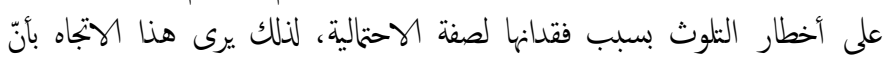

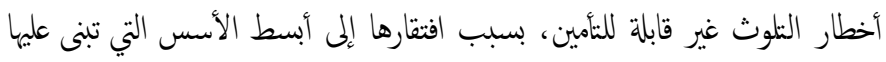

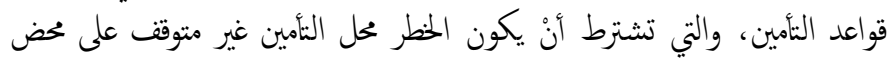

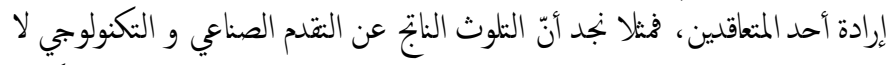

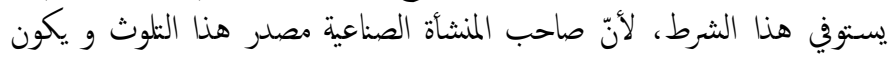

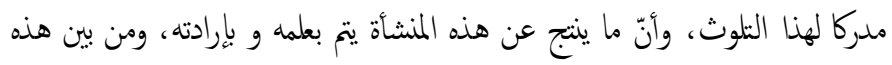

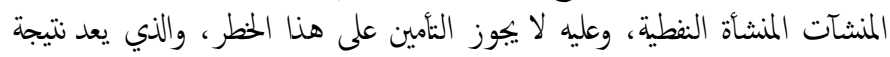

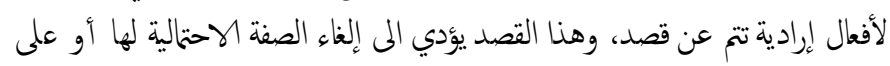

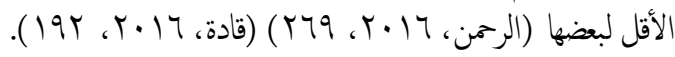




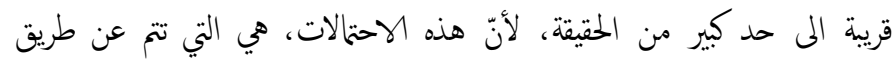

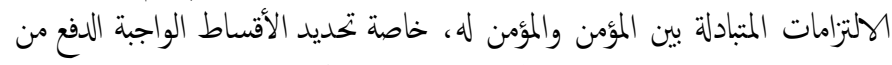

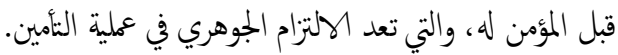

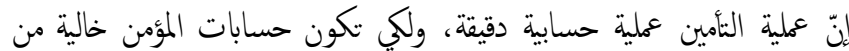

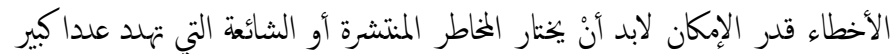

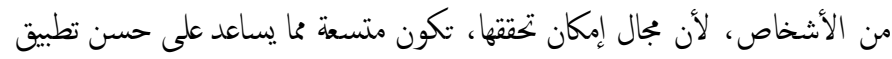

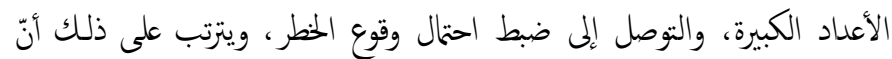

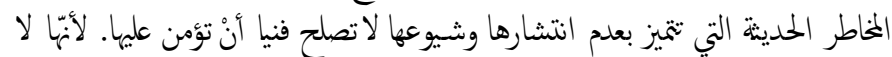

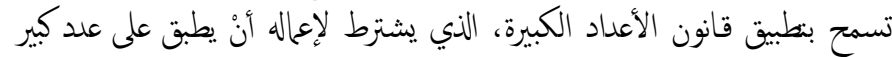

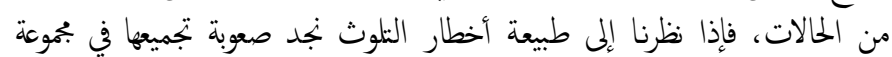

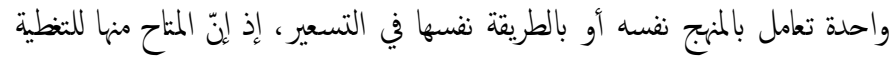

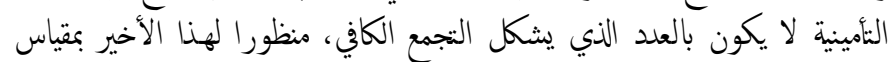

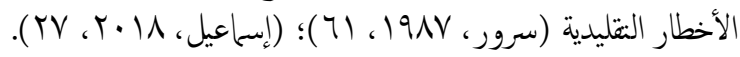

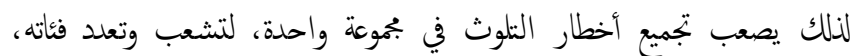

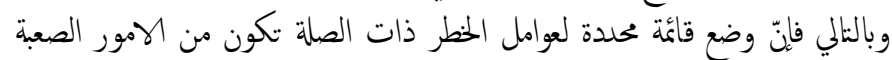

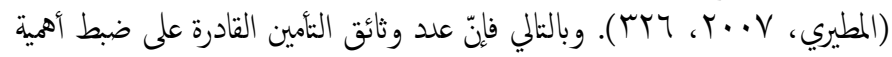

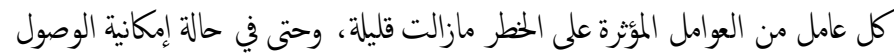

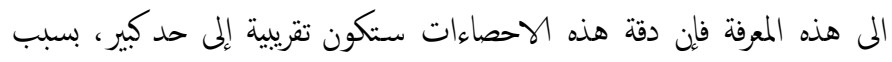

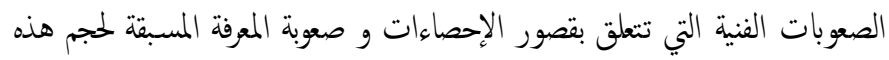

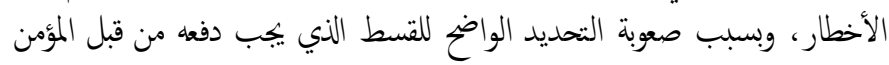

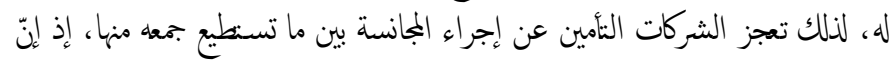

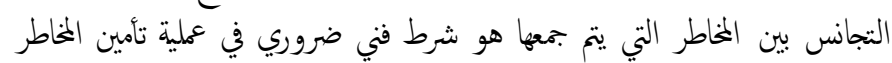

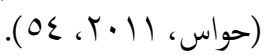

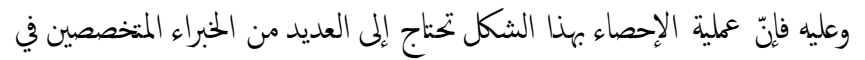

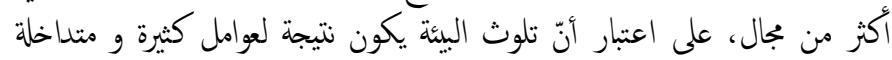

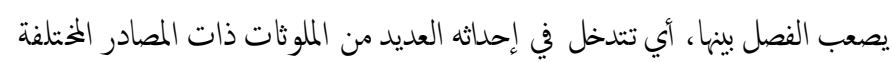

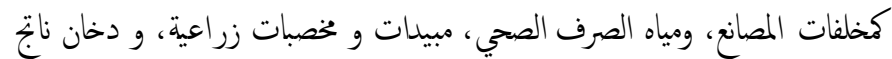

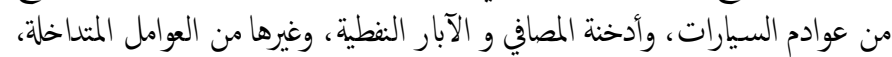

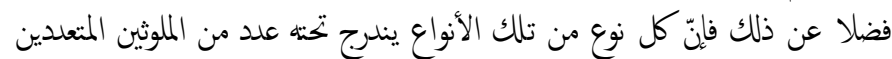

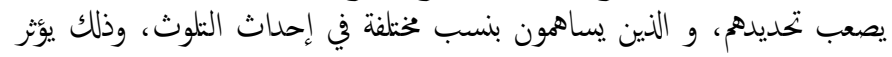

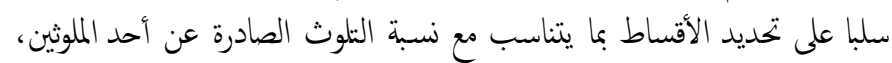

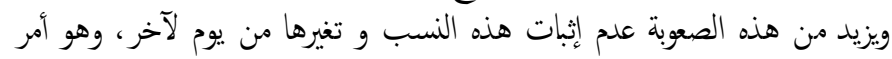

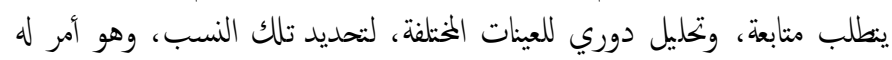
تأثيره على مقدار الأقساط الواجبة الدفع.

ب. أخطار الثلوث وكون الخطر موزعا أو متفرقا:

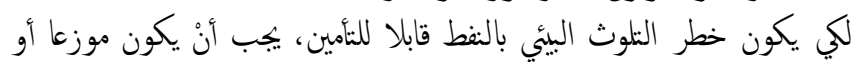

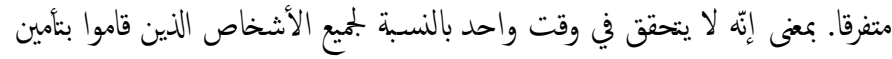

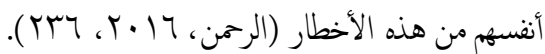

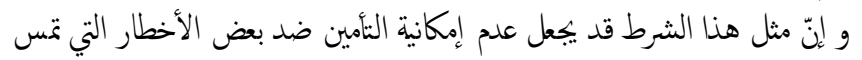

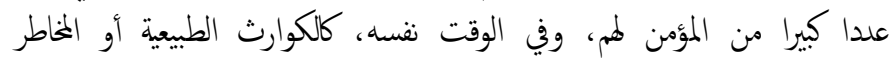

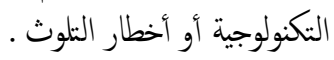

عرضيا تماما، ناتجا عن حادث احتمالي وليس عن طبيعة النشاط محل الممارسة، أي

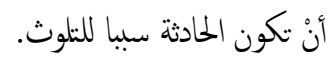
والأمر الذي لا شك فيه أنّ ربط الحادثة بها التصور، أي بفكرة الاحتال قول

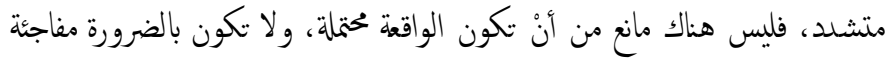

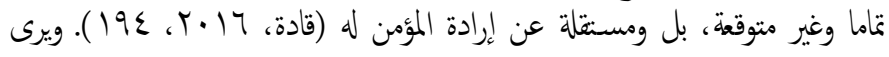

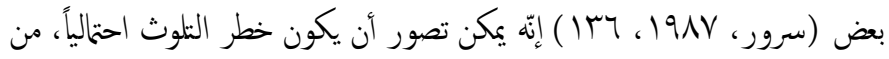

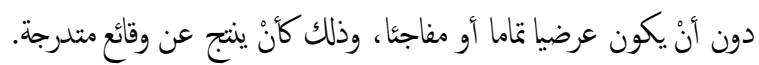

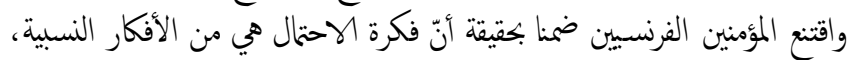

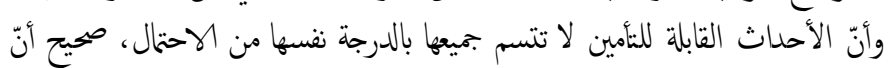

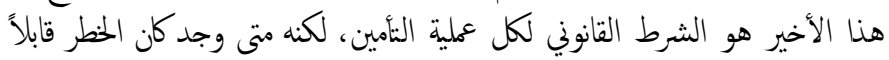

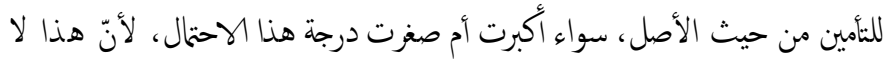

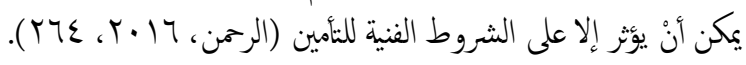

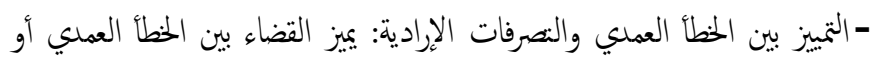

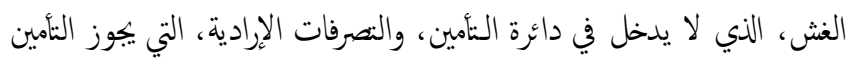

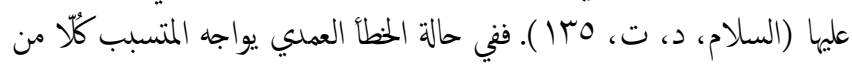

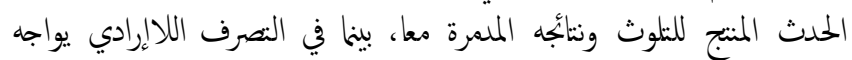

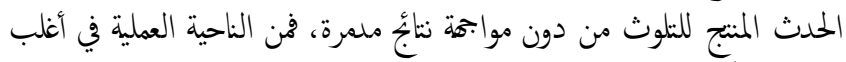

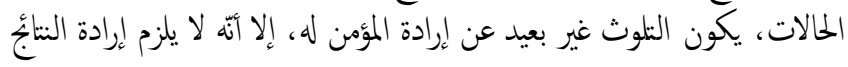

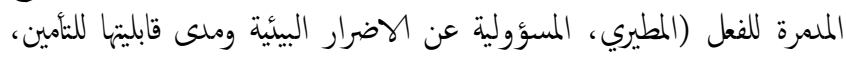

(r)

- التضييق القضائي لمفهوم الخطأ العمدي: لقد صار اليوم الخطأ العمدي غير كاف

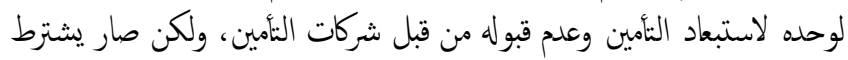

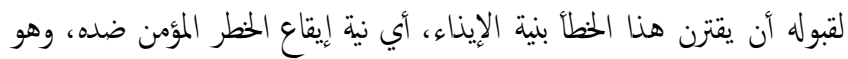

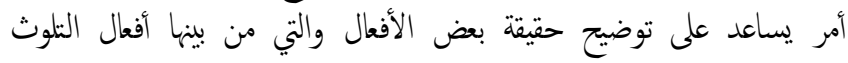

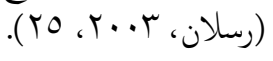

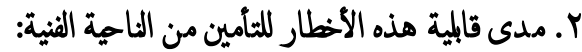

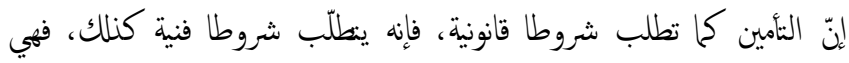

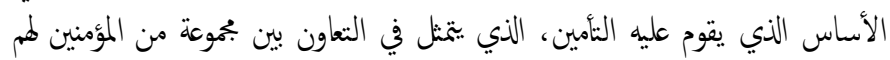

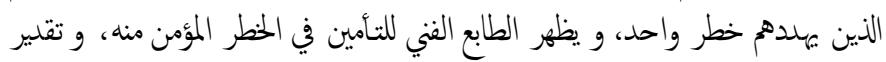

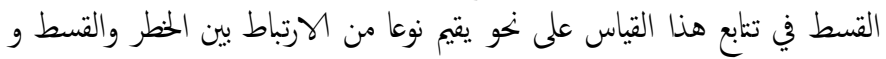

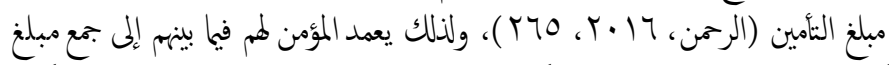

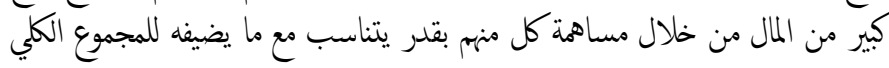

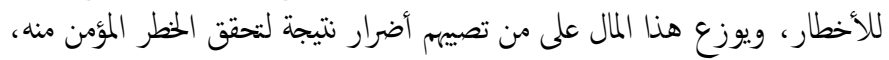

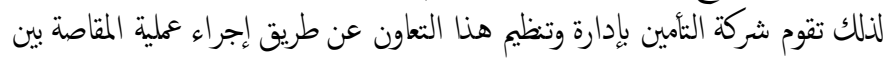

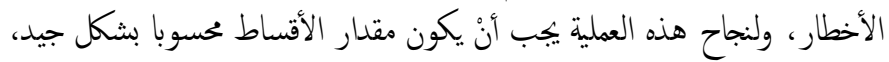

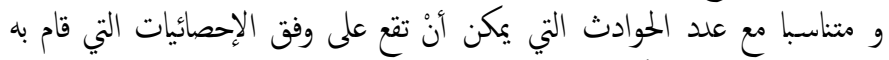

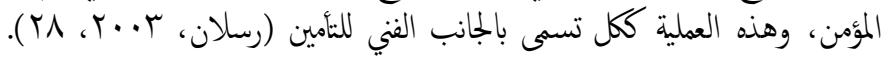

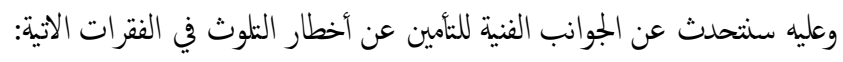

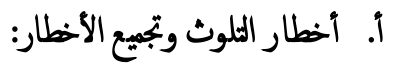

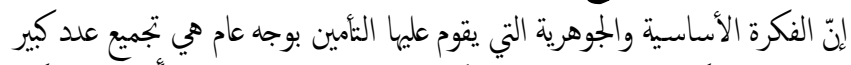

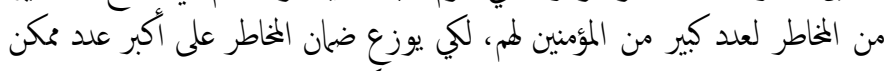

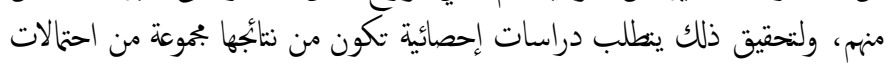


وعدم توقعها، لذلك يفشل المؤمن من وضع نظام تأميني يحتوي على كفة الاضرار

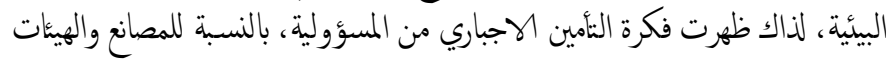

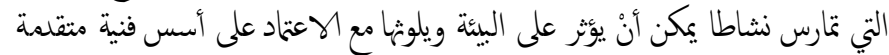

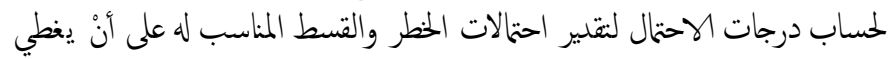

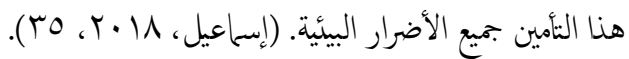

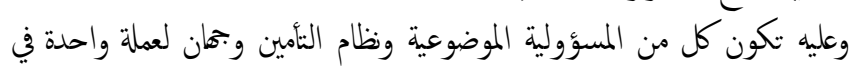

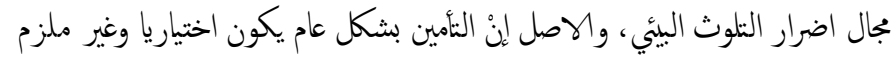

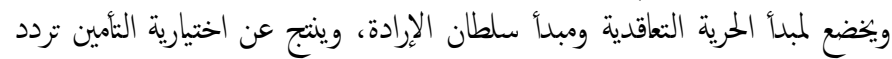

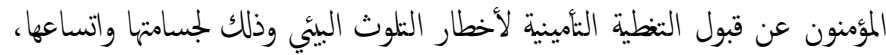

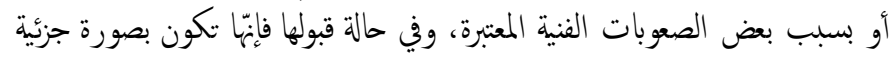

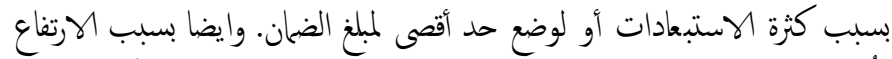

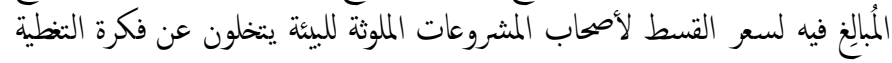

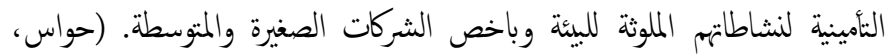

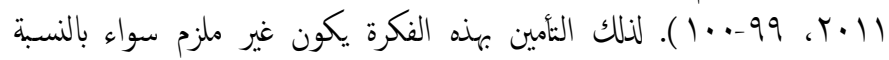

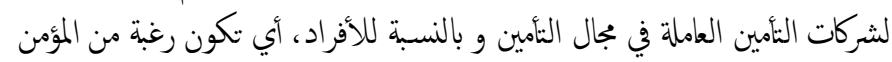

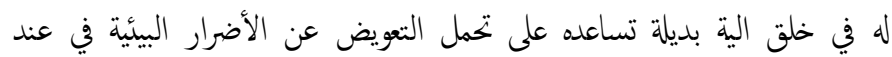

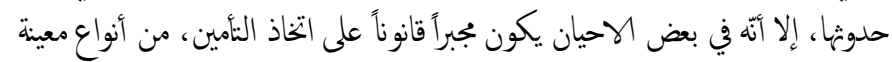

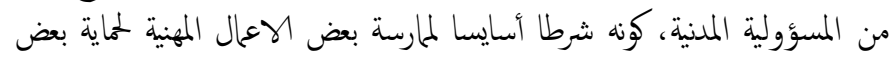

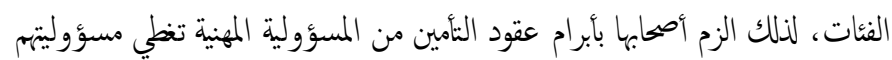

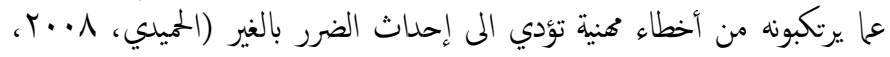

. 094

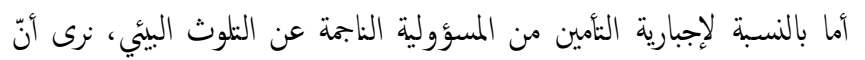

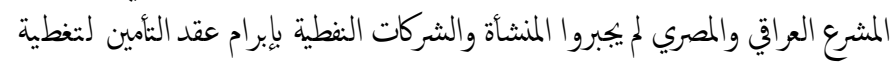

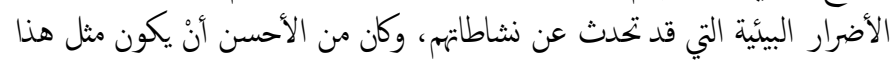

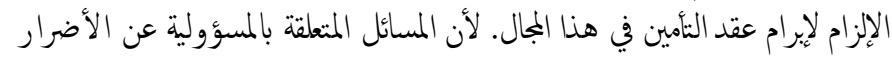

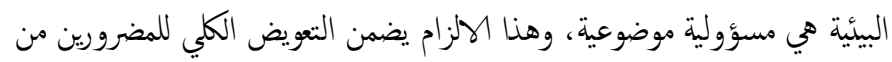

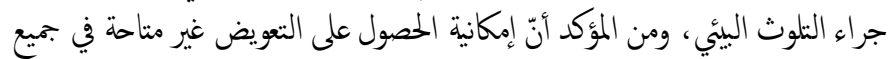

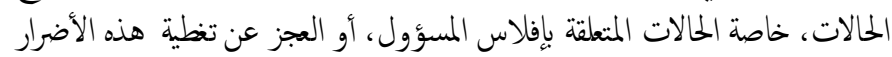

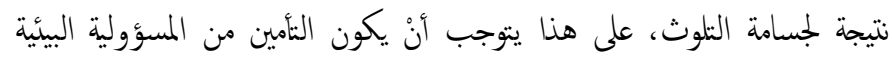

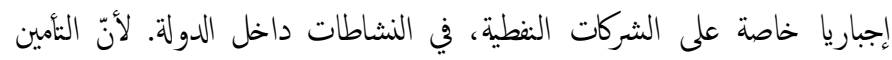

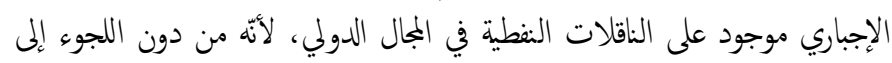

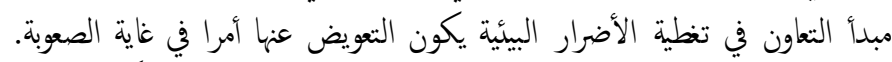

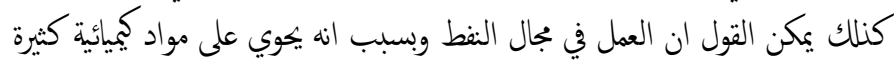

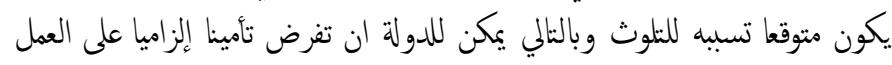

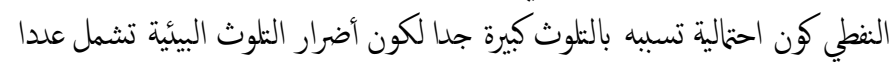

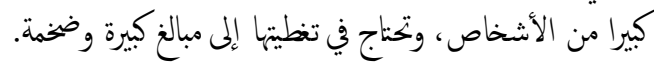

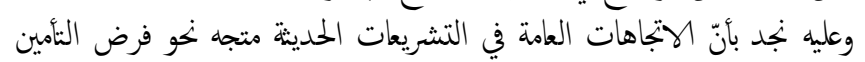

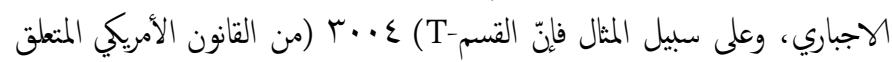

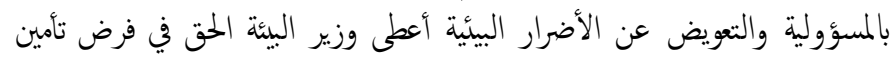

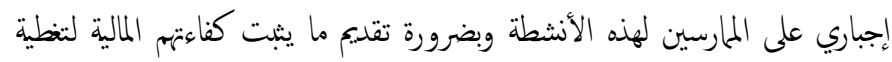

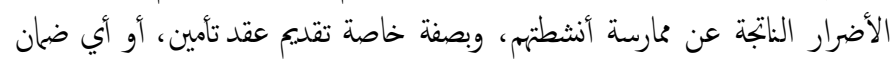

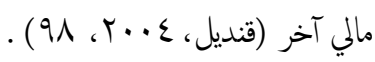

و بالنظر إلى أخطار التلوث نرى بأنها لا تتصف بالعمومية، بحيث يصعب تفطيتها

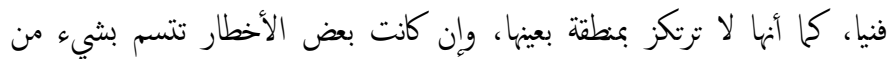

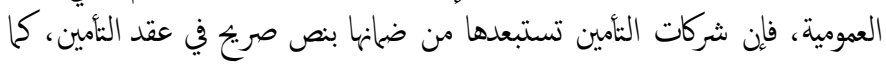

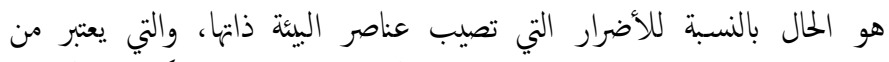

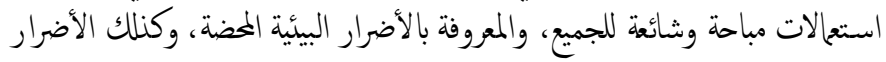

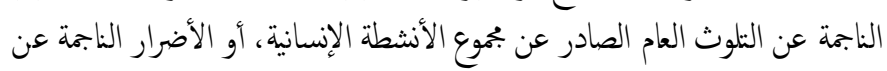

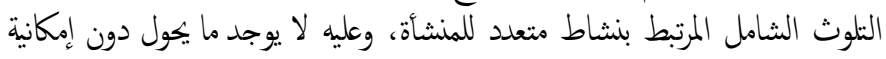

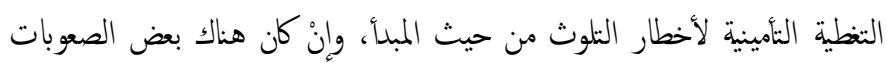

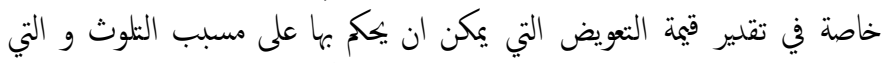

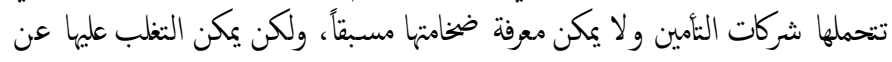

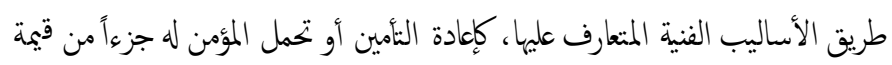

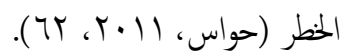

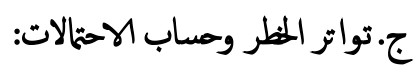

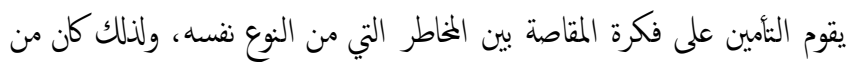

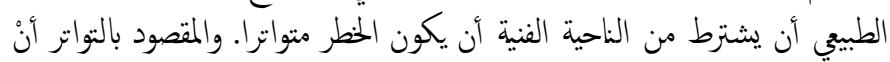

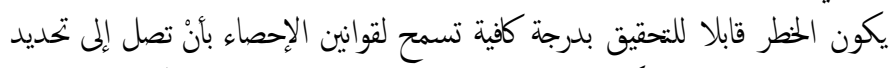

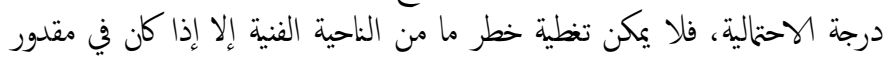

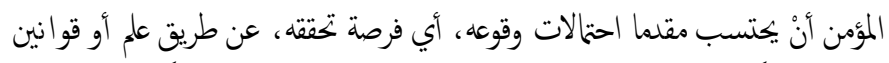

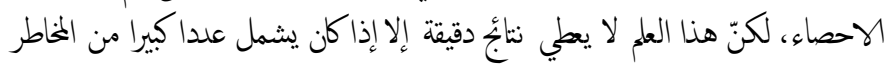

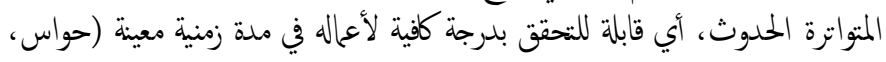

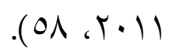

فالثأمين يزتكز على أساس حساب الكتمالات، وحساب الاحتالات، معناه

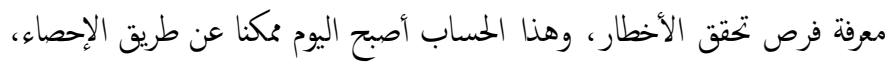

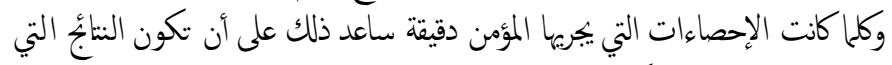

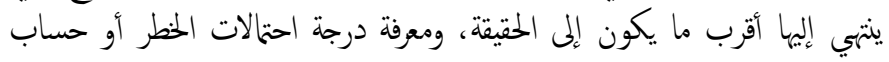
الاحتمالات قد بات اليوم مككنان بفضل تقدم فن الإحصاء.

\section{r.Y المطلب الثاني: التأمين الاججاري عن أضرار التلوث البيني والمثكلات

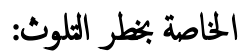

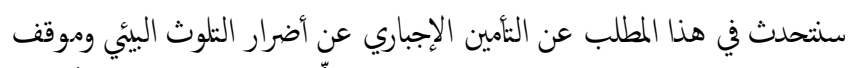

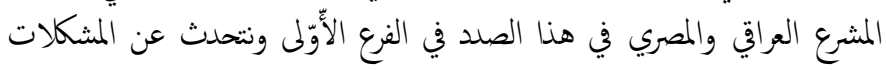

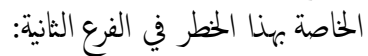

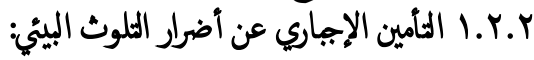

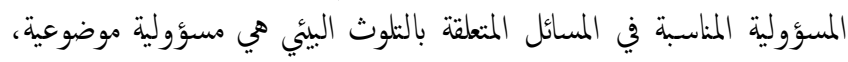

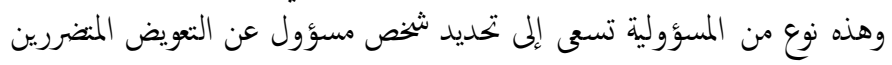

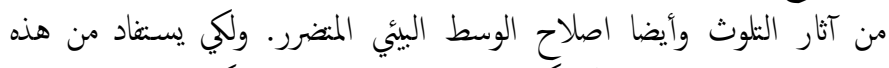

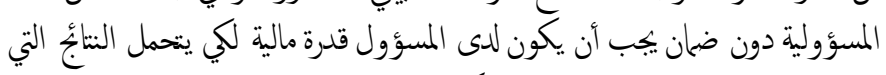

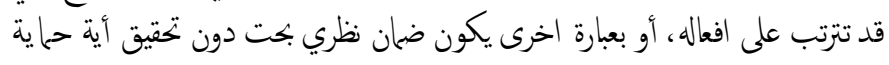

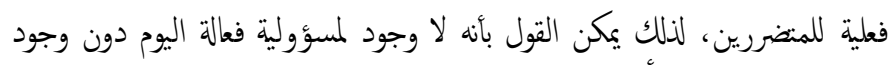

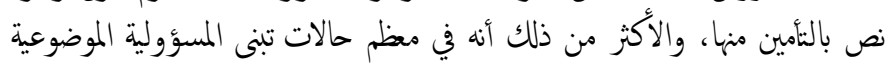

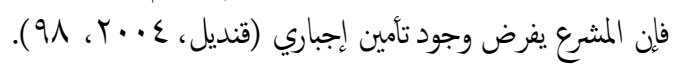

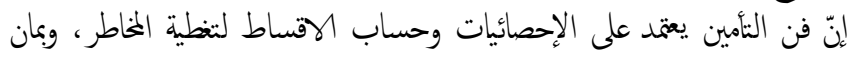

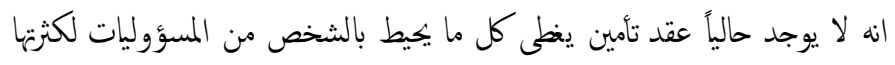


اكتشف في السنوات المنسة السنوات التالية لهنا التوقف (سرور، 19NV،

.( Ir人

ثانيا:مشكلة التنوث المتعلد المصادر: في حالة مشاركة أكثر من مصدر في حدوث

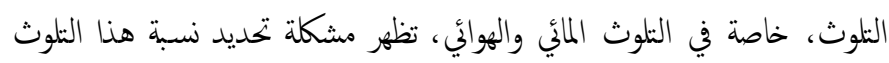

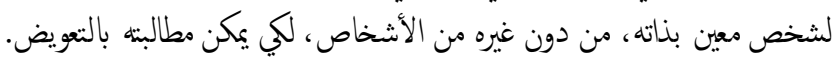

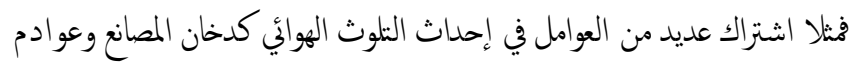

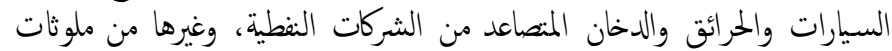

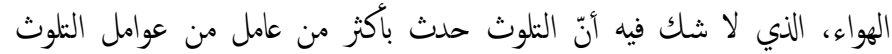
الهوائي، ولكل مصدر مشاركة بنسبة في التلوث.

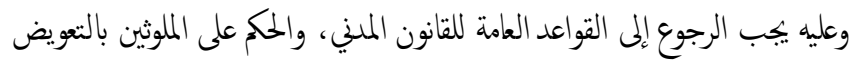

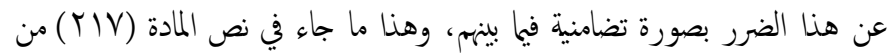

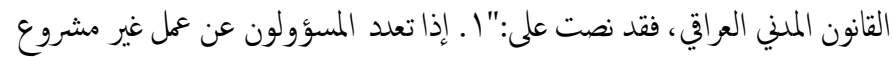

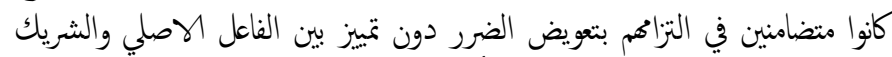

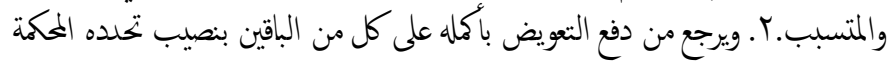

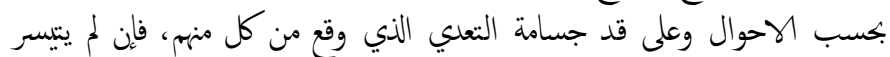

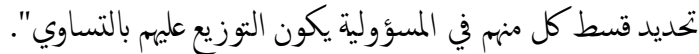

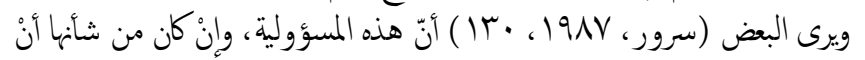

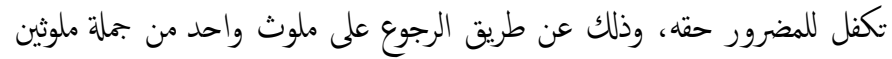

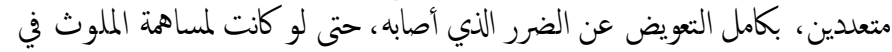

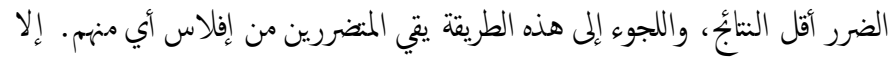

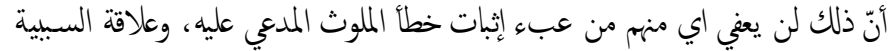

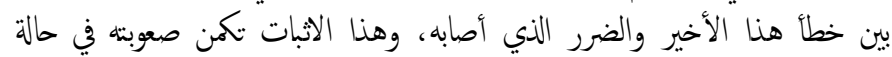

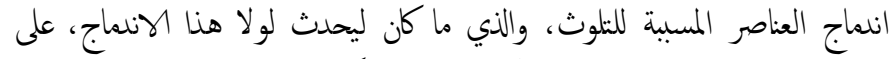

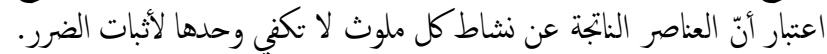

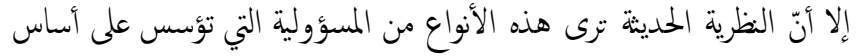

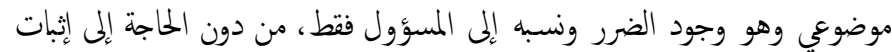
الخطأ، وهنا يعد كفيا للحصول على التعويض.

\section{r. نظام الصناديق كالية جديدة لثعويض ضحايا الثلوث البيتي}

إذا كان خطر التنوث محلا للتأمين من المسؤولية، فتعويض المضرور من التلوث

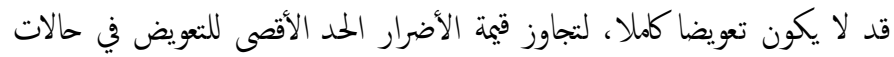

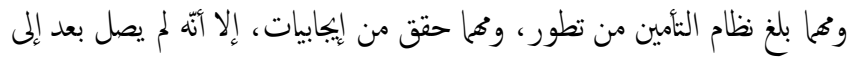

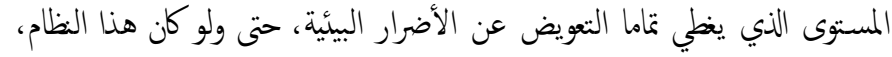

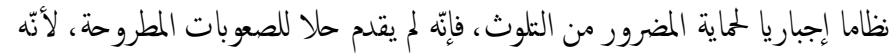

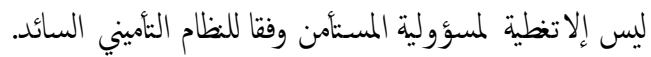

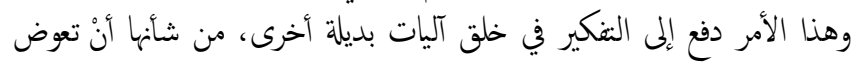

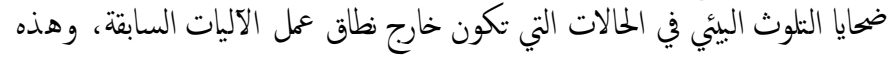

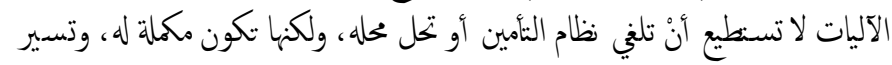

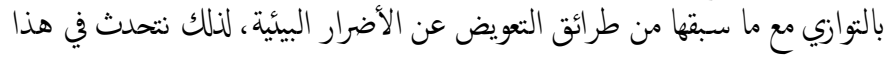

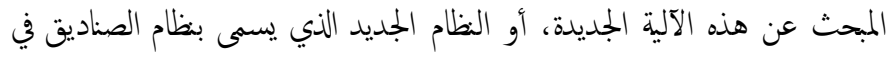

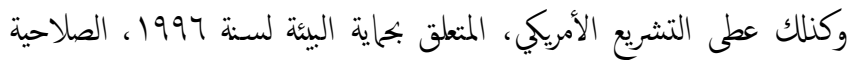
لوكالة حاية البيئة (E P A) في متابعة الشركات مصدر التنوث في حالة عدم توافرها

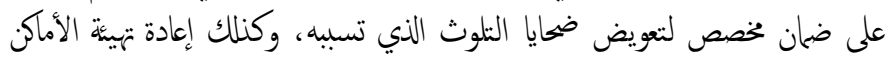

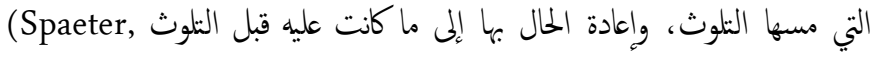

. (r Tq, r. T

وفيم يخص واقع التأمين على القطاع النفطي على مستوى الدولة الاتحادية العراقية

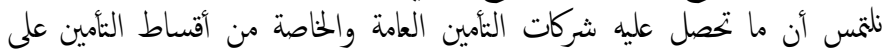

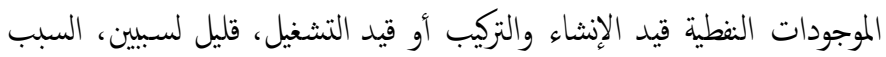

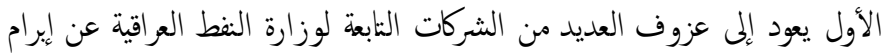

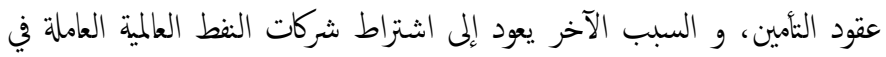

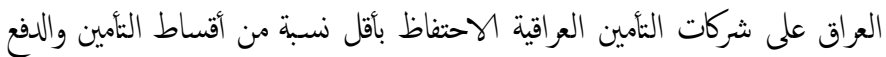

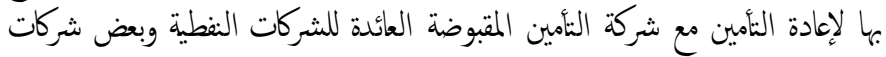

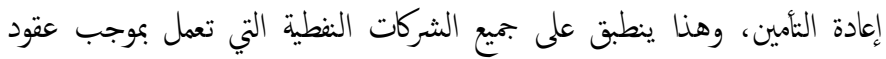

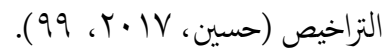

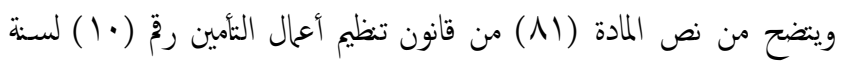

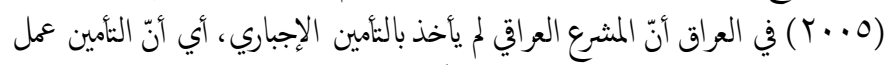

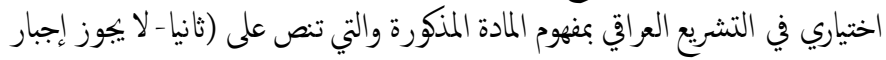

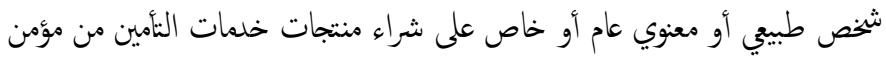

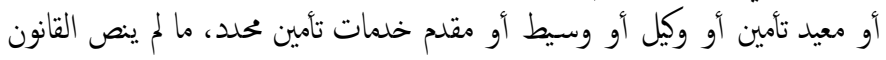
على خلاف ذلك).

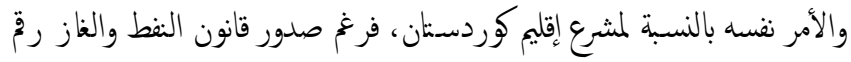

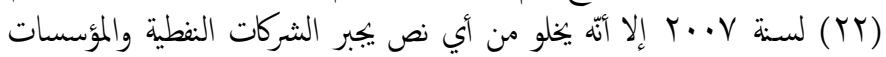
النفطية على التأمين بشكل عام.

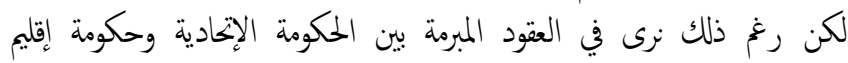

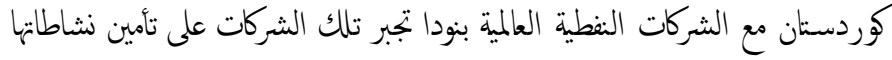

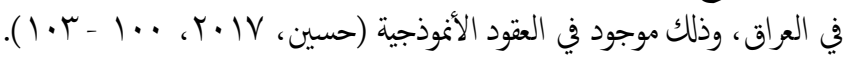

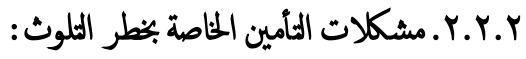

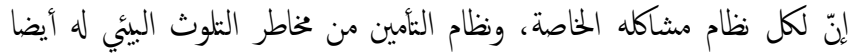

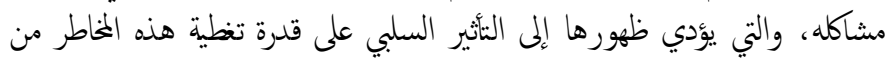
قبل المؤمنين، وسنبين هذه المشاكل فئ في الفقرتين الاتيتين:

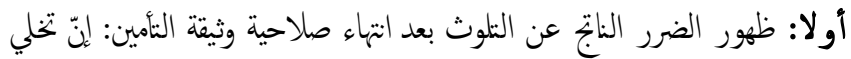

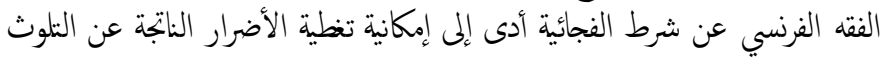

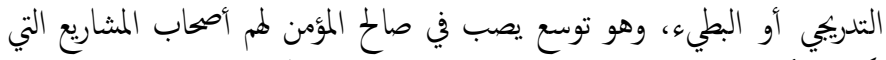

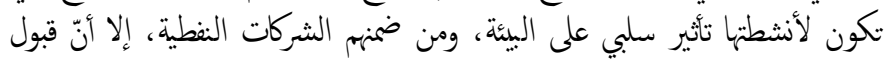

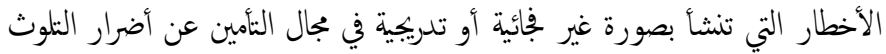

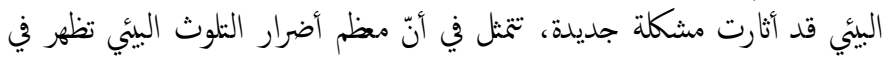

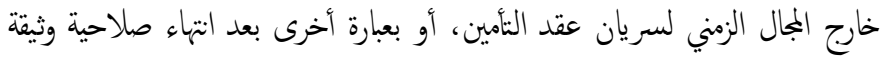

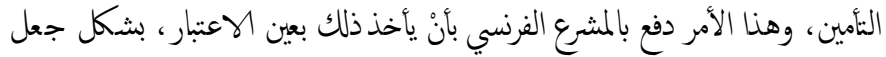

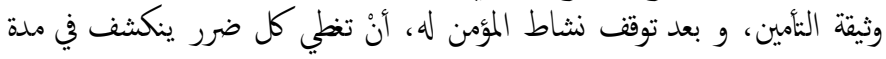

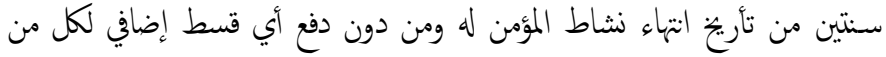
يطالب بتعويض عن ذلك الضرر. وبلفع قسط إضافي إذاكان هنا الضرر قد ظهر أو أو 
وكناك الصندوق (Superfund) الذي أنشأبموجب القانون الأمريكي (Cercla) الصادر في سنة • 191 الخاص بتعويض المضرورين من جراء ماركارسة الأنشطة البيئية

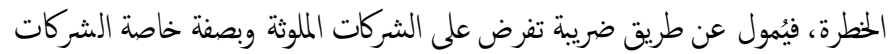

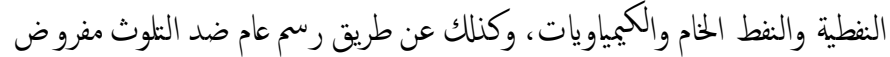

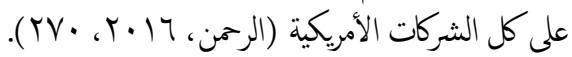

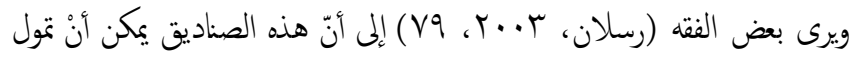

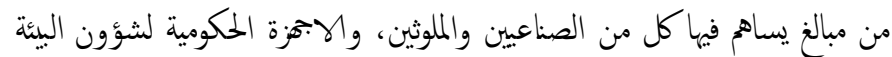

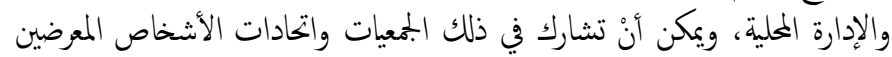

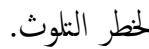

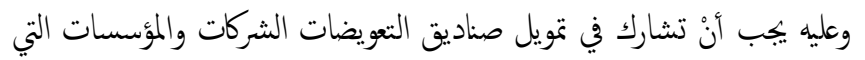

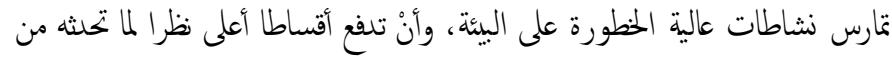

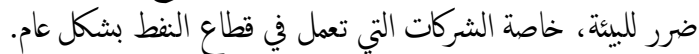

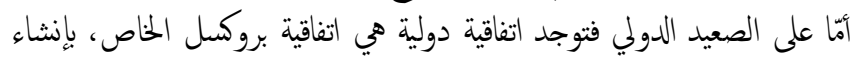

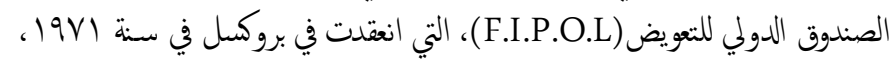

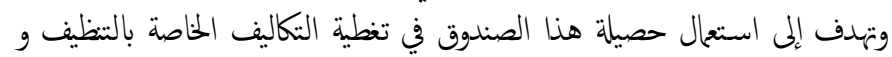

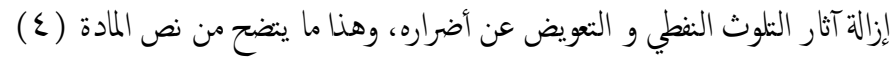

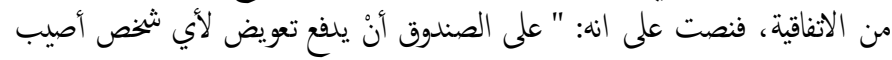

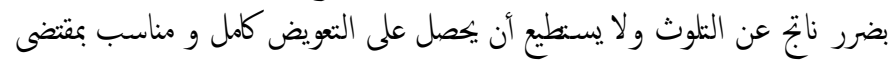

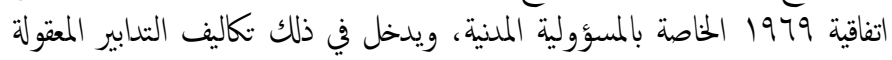

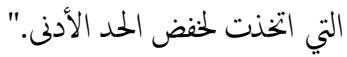

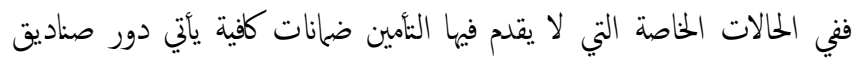

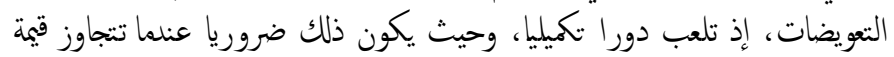

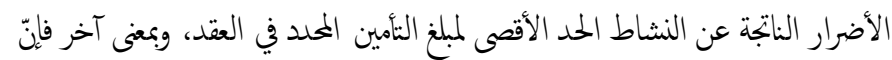

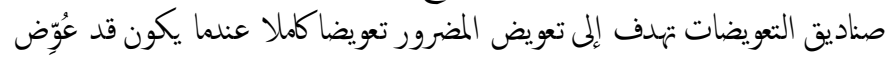

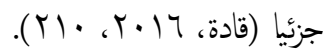

\section{r.r r. المطلب الثاني: نظام الصناديق الييئة في المراق ويعض الدول الأخرى:}

في هنا المطلب نتحدث عن نظام الصناديق للتعويض عن النلوث البيئي بالنفط في العراق ومصر وفرنسا في الفروع الأتية: r.r.r.r الفرع الأول: ظام صنادئ التروع التعويض البيني في العراق:

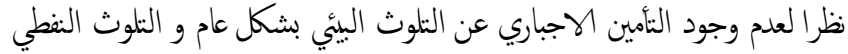

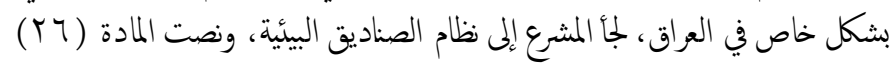

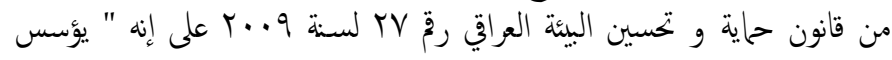

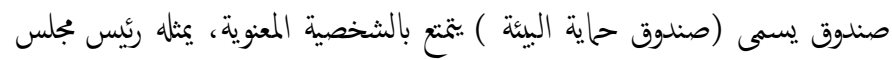

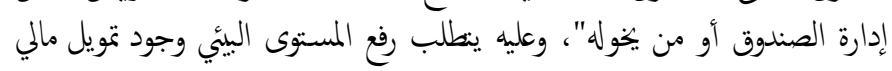

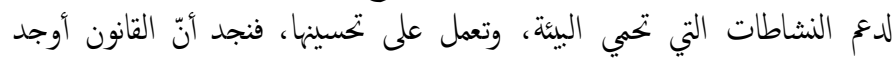

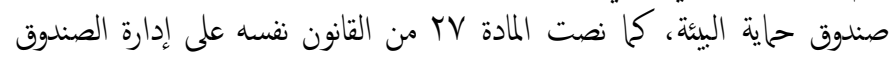

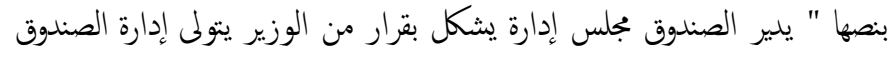

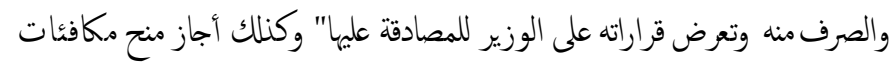

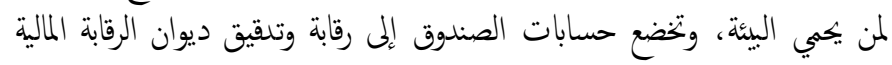

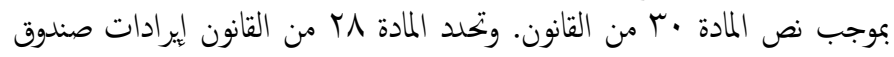

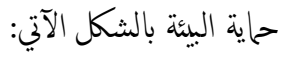

المطليين متثالين في نشأة الصندوق، ووجود هذا الظظام في القانون العاقي، وقوانين

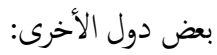

\section{r.1 المطلب الأول: نثأة الصناديق ودورها في إطار تعويض الأضرار الناتجة عن}

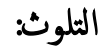

ظهرت فكرة إنشاء صناديق التعويضات من أجل الوصول إلى العدالة والتويض

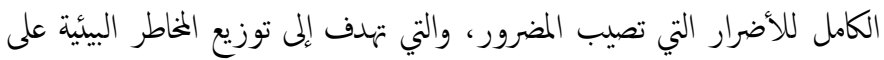

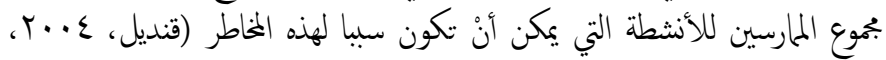

وهذه الصناديق عبارة عن حسابات مالية تفتح لدى الدولة على الميزانية العامة للادولة، وتكون سلطة الأمر بالصرف فيها للجهة المختصة بحاية البيئة.

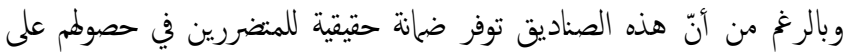

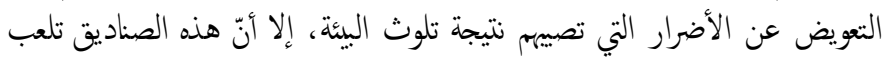

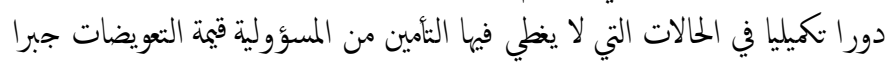

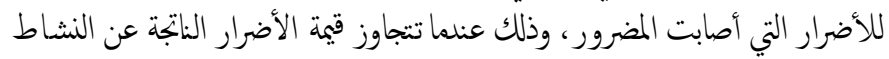

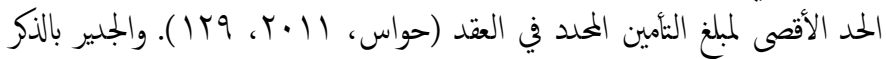

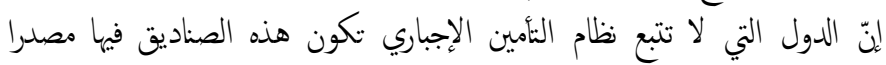

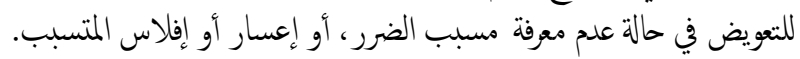

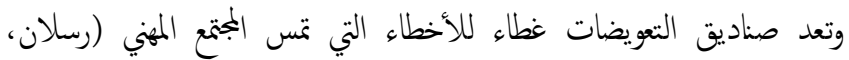

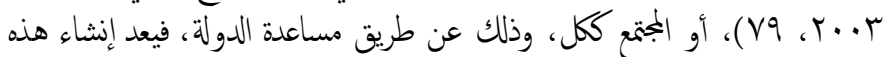

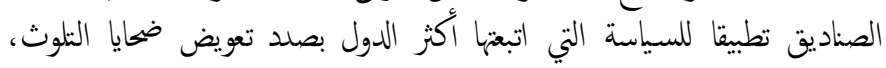

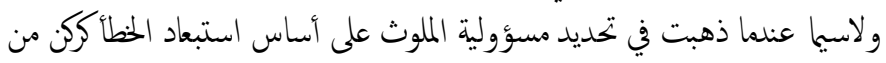

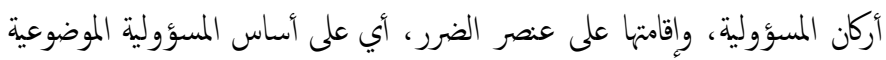

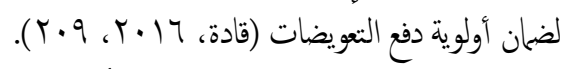

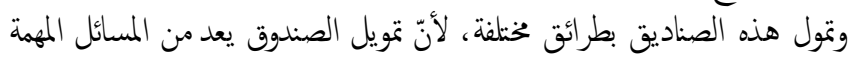

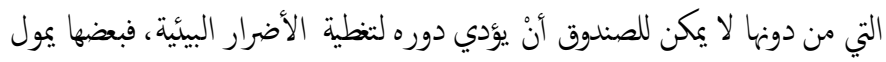

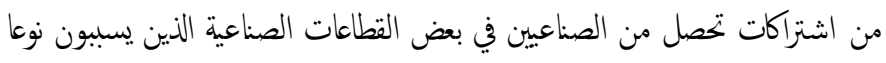

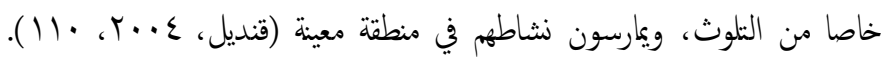

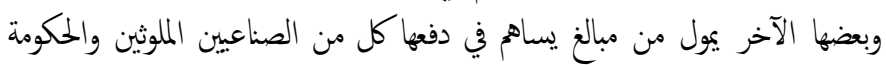

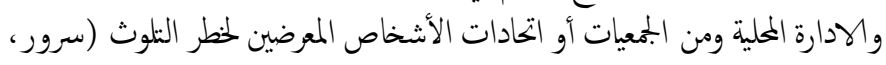

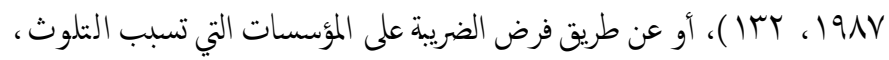

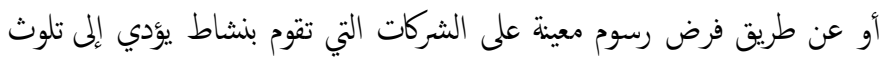
البيئة. أمّا المشروع الفرنسي المتترح لصندوق النتويض لضحايا التلوث العارض

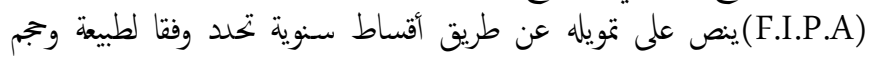

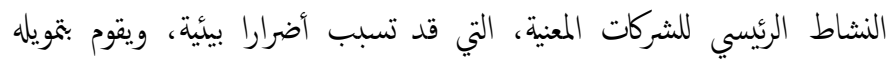

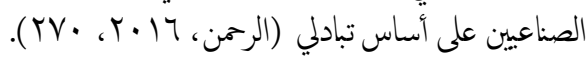

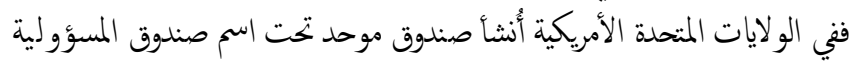

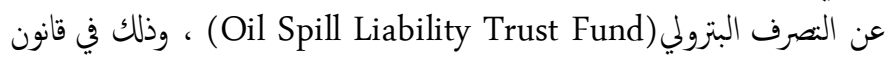

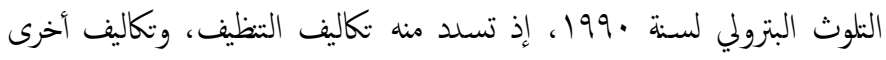

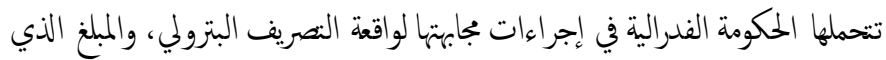

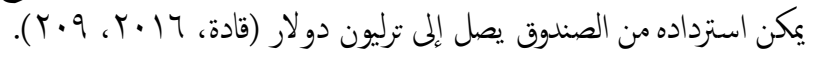


وحلدات المادة (7) من تعليمات الصندوق البيئي وواردات الصندوق والتي :كون بالشكل الآتي : بات الماد:

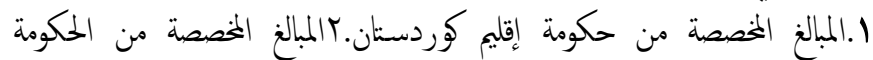

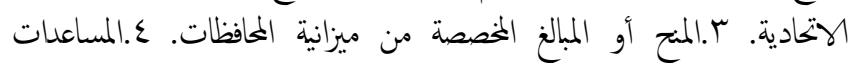

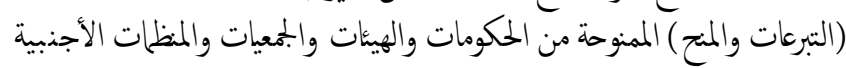

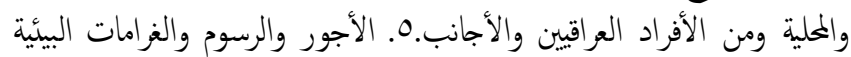
المستوفاة بموجب التشريعات النافذة.

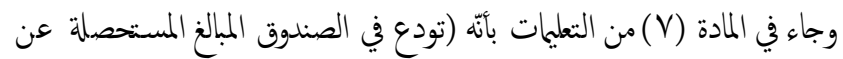

الأضرار التي لحقت بيئة الإقليم).

ونصت المادة (Tا ) منها على أنّه (في حال عدم قدرة المجلس على تحقيق أهلافه

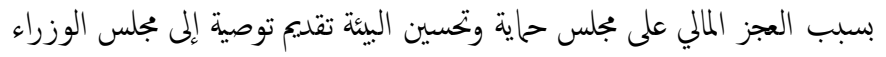

بضرورة توفير المال اللازم لقيام المجلس بأداء محامه وتحقيق أهدافه).

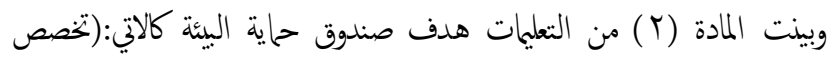

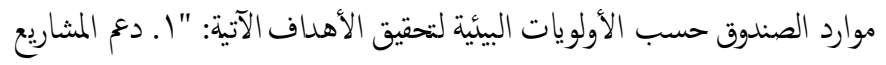

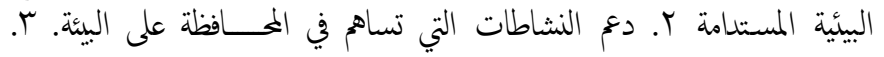

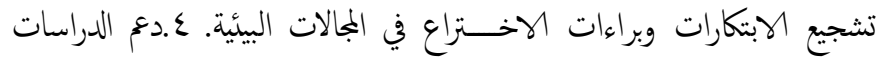

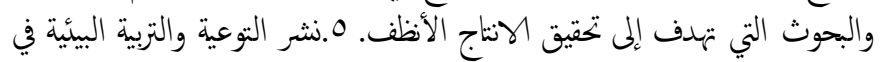

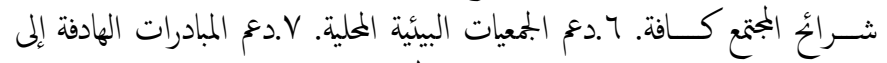

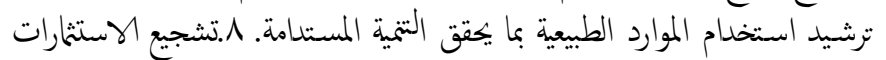

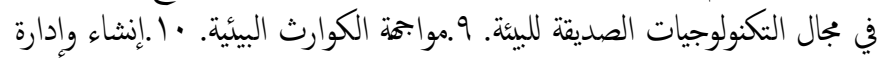

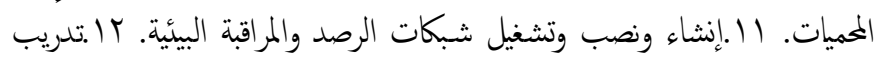

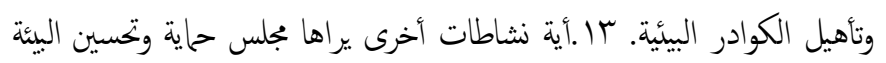

تخدم أهداف الصندوق.".

ويؤخذ على أهداف الصندوق أنها لم تُبين بوضوح تعويض الأضرار البيئية التي

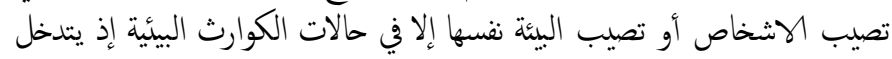

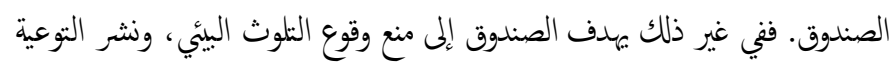

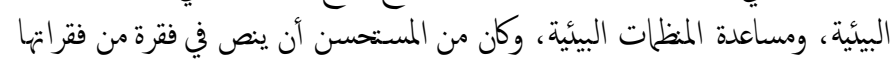

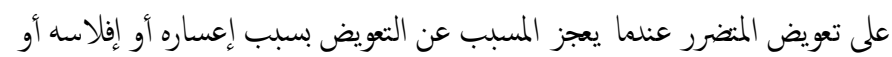

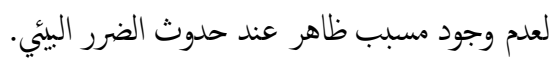

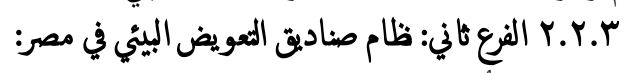

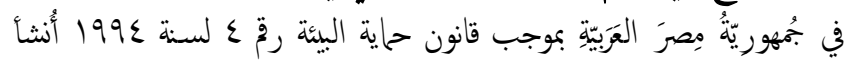

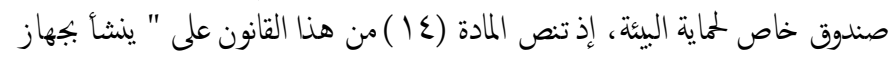

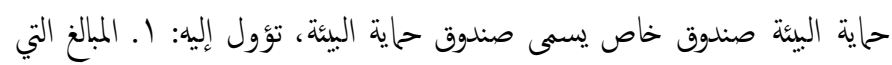

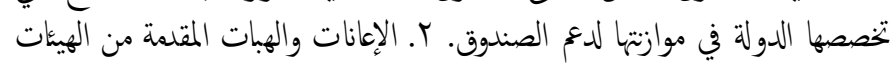

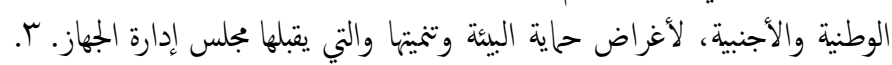

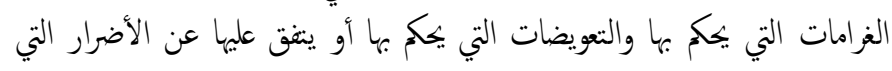

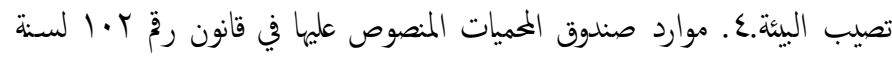

.1914

وتودع في الصندوق - على سبيل الأمانة- المبالغ التي تحصل بصفة مؤقتة تحت

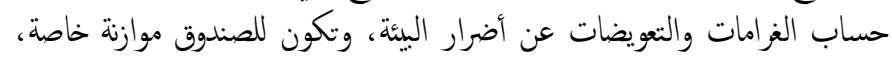

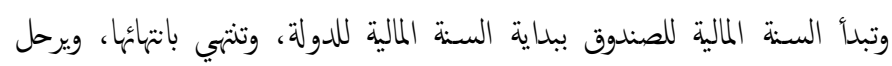

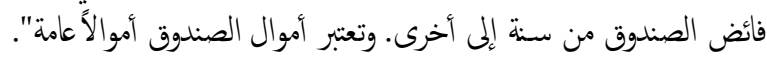

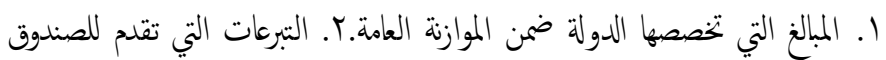

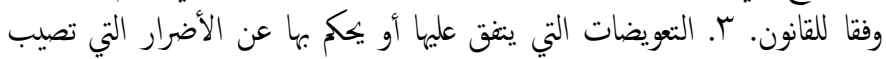

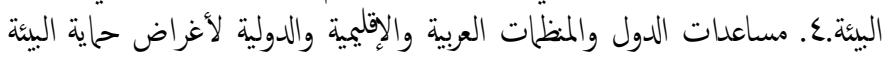

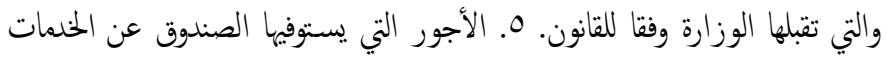

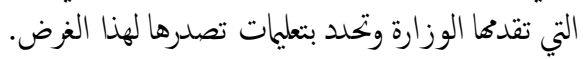

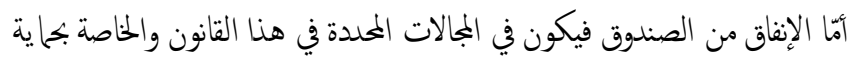

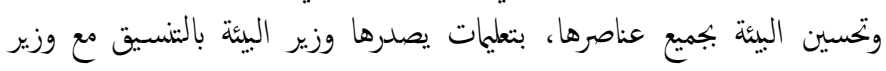
المالية. ويُحدد التعويض اللازم دفعه من قبل مرتكب الخطا أو المسؤول عنه وفقا للقواعد

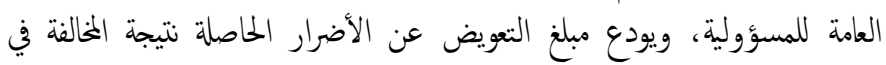

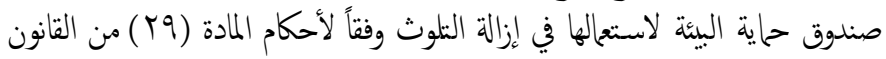
والتي تشترط الانفاق على المجالات الخاصة بحاية وتحسين البئة الئة.

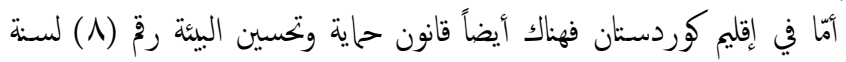

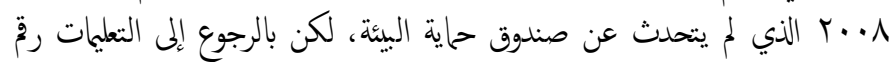

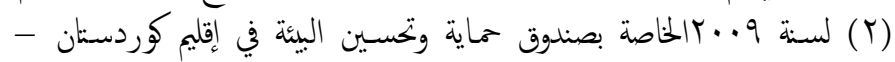

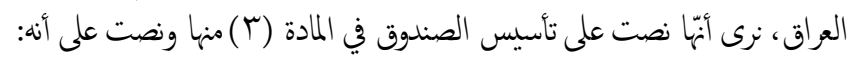

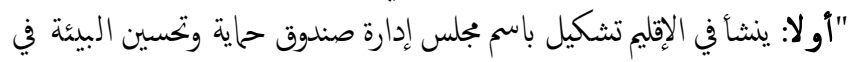

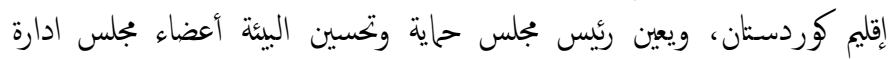
الصندوق بعد موافقة أغلبية أعضائه المكون كما يلين:

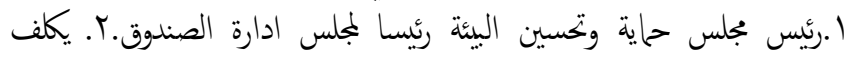

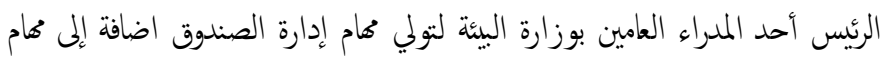

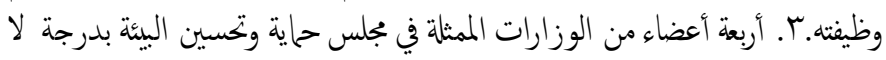

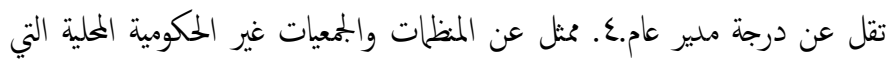

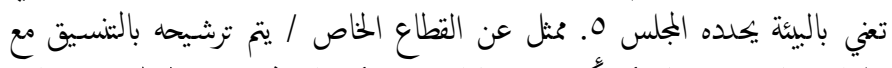

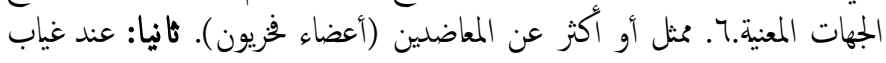

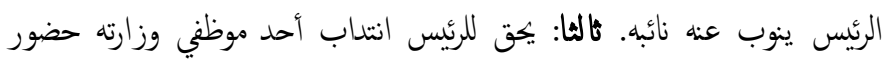

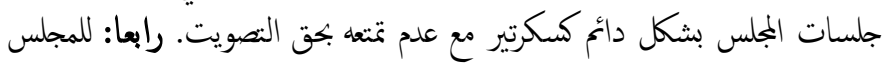

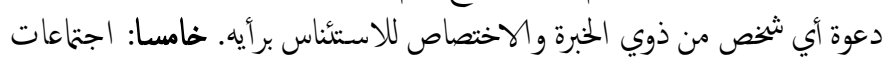

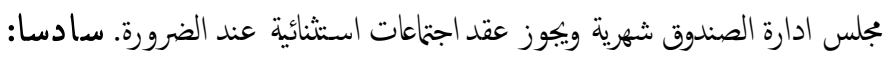

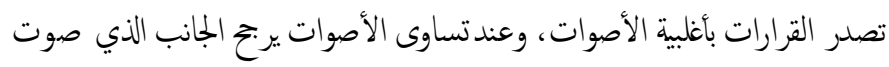

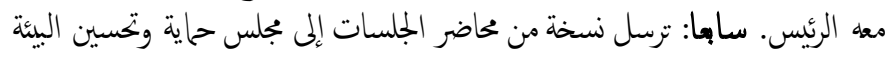

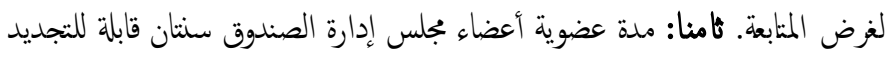

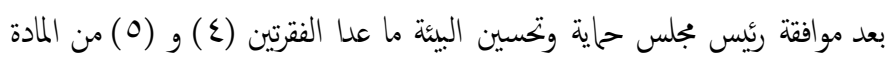

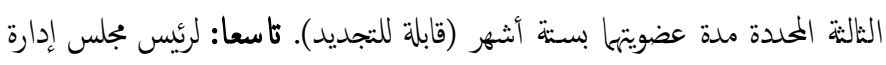

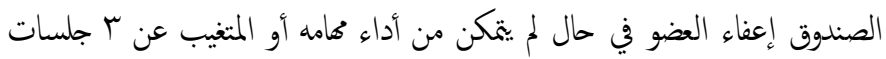

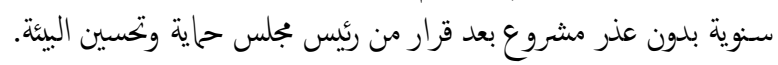

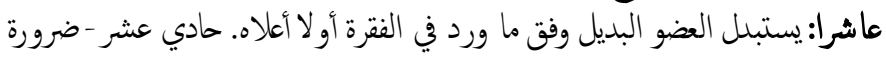

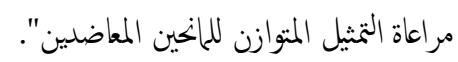

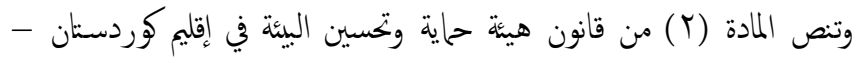

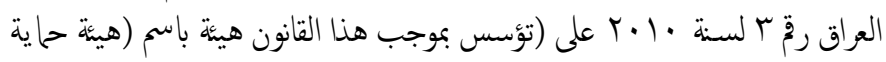

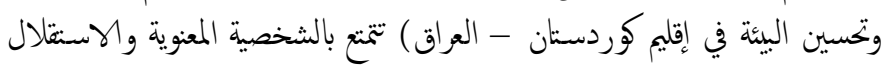
الملالي والاداري، وترتبط إدارياً برئاسة مجلس الوزراء). 


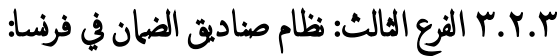

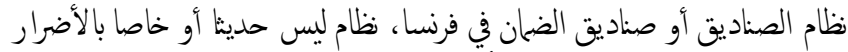

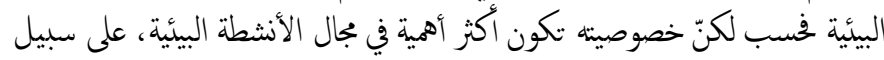

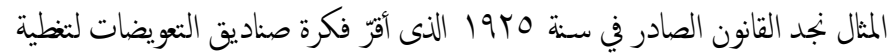

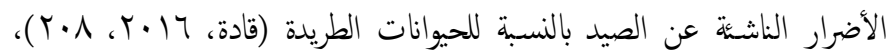

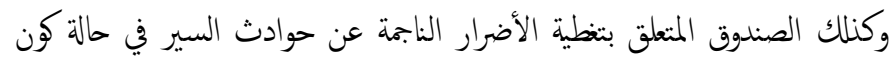

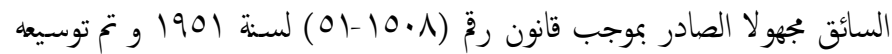

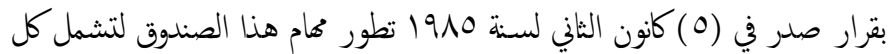

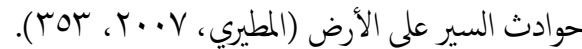

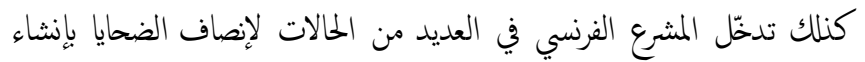

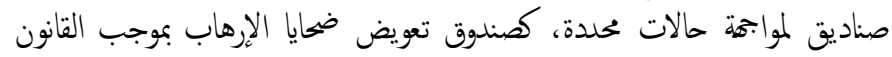

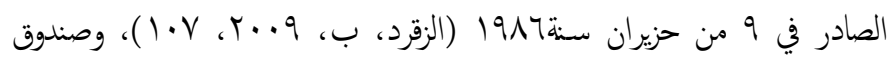

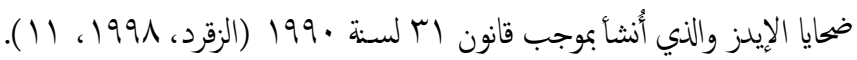

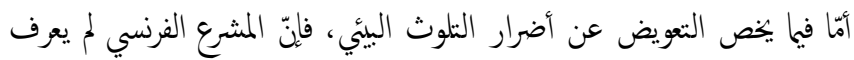

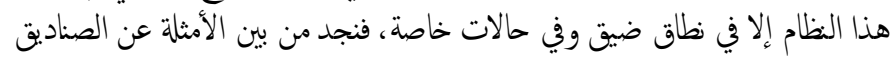

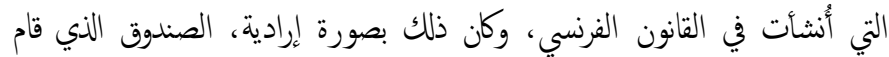

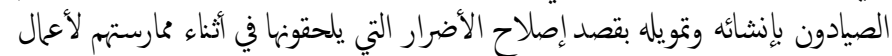

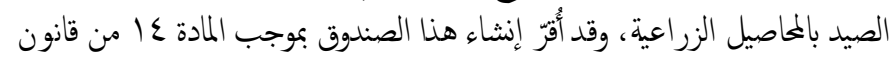

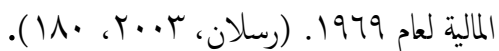

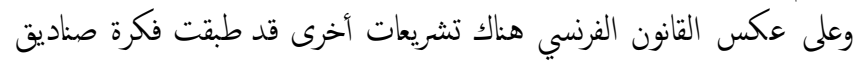

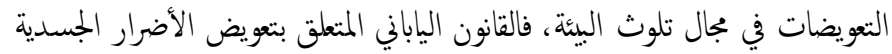

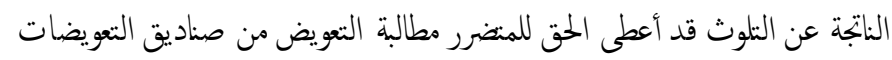

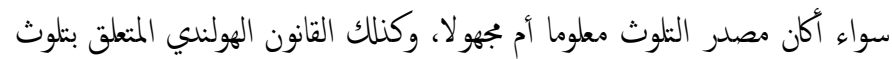

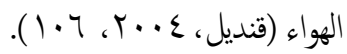

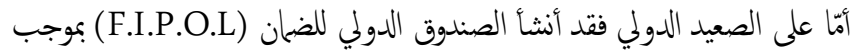

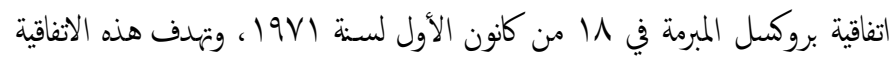

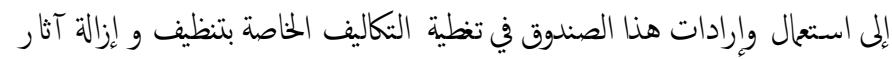

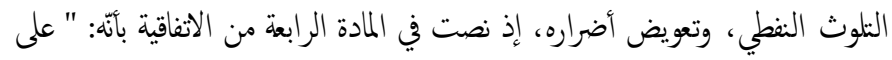

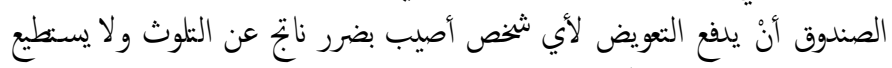

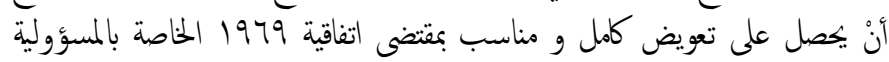

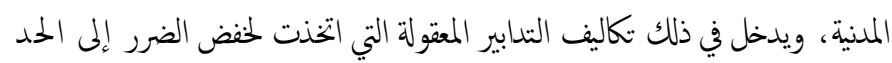
" الونى

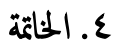

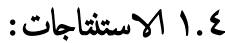

ا ـ بالرغ من اختلاف التعريفات حول التأمين من المسؤولية يكن القول بان الهدف

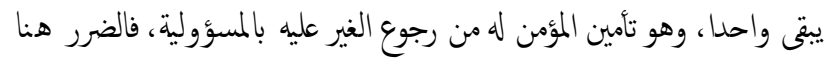

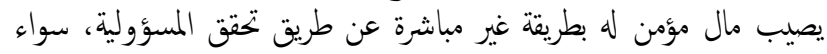

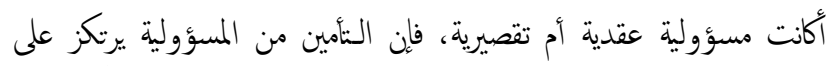

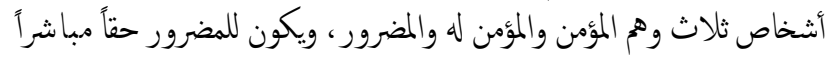

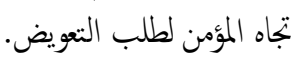

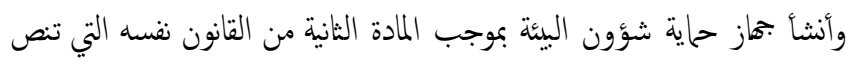

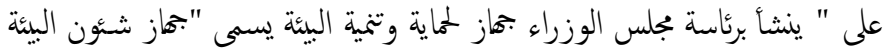

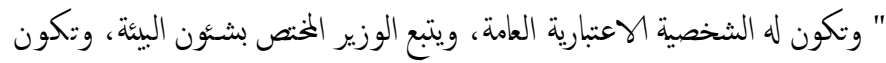

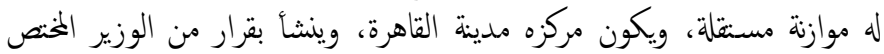

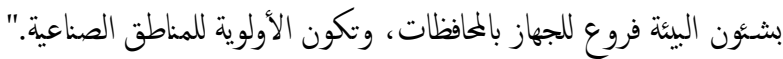

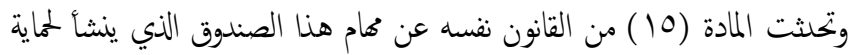

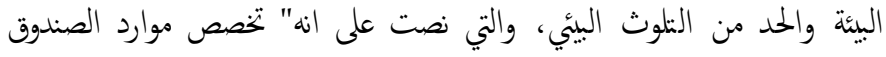

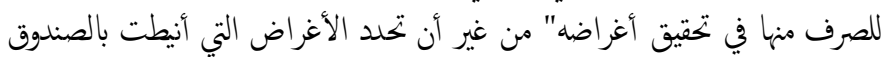
لكي يعمل لنحقيقها. لكن اللائحة التنفيذية لقانون البئة الصادر بالقانون رقّ ع لسنة ع 199 ، والتي

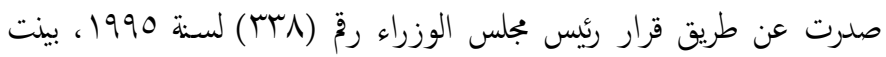

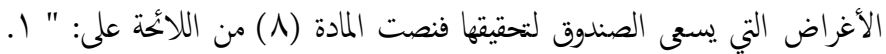

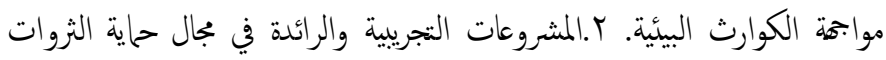

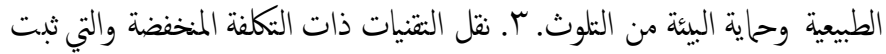

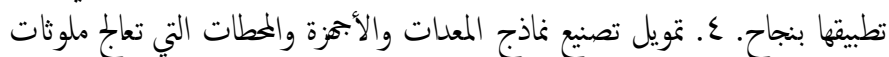

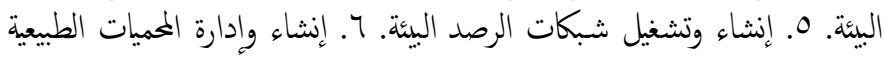

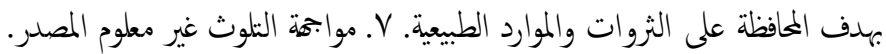

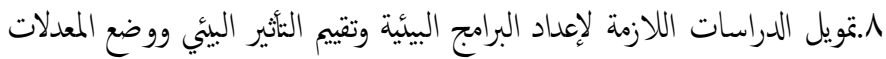

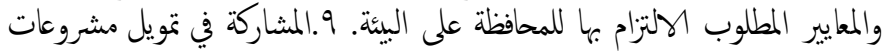

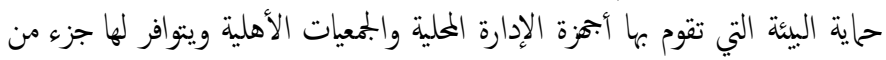

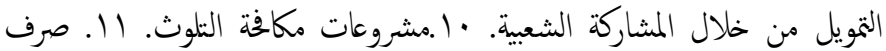

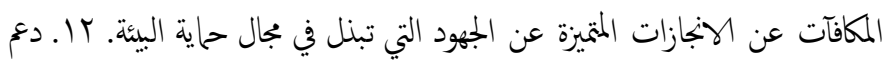

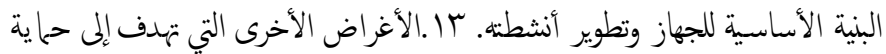

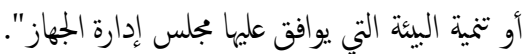
بعد تحليل هنا النص نجد أنه قد أورد حالات كثئ النيرة لنحقق الصندوق هلفه

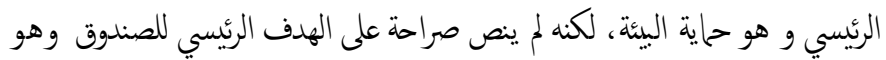

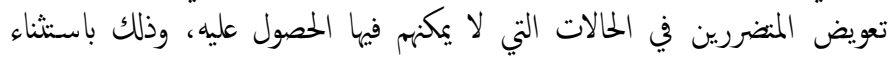

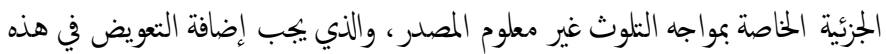

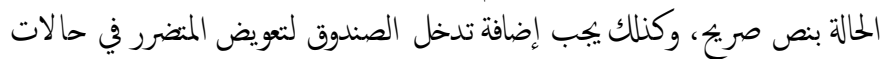

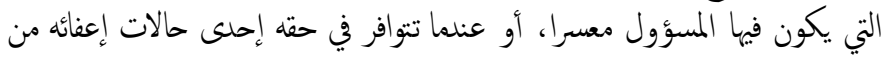

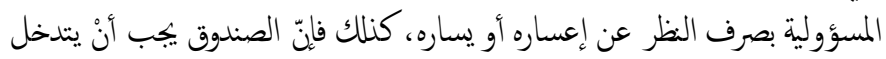

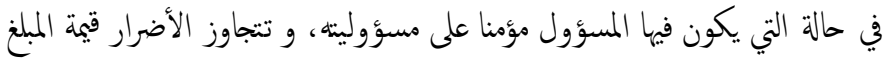

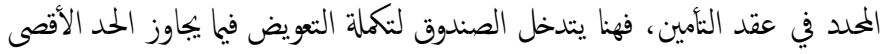

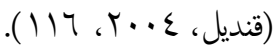

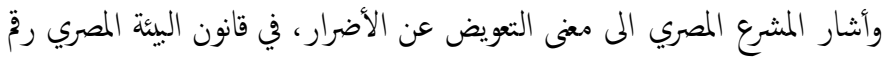

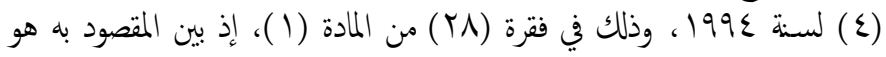

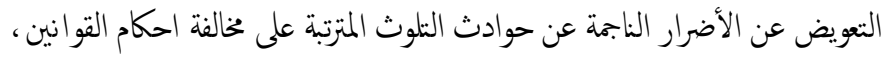

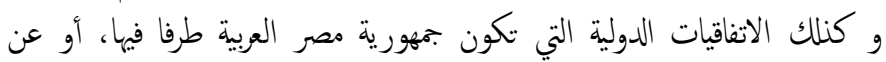

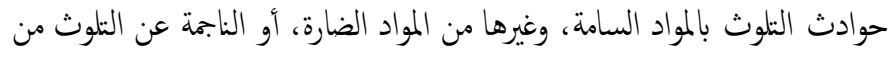

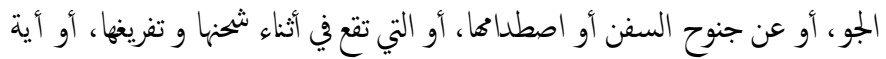

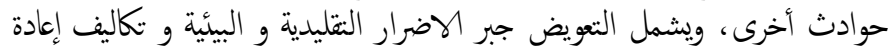
الحال لماكانت عليه، أو إعادة إصلاح البيئة. 
حسين، د. ف. (YV) (Y). التأمين على مخاطر الصناعة النفية- دراسة مقارة بين القاونين العراقي والنرويجي.مجلة جامعة التنمية البشرية، مجلدس(ب) (Y)، 99.

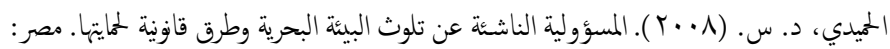
دار الجامعة الجديدة.

حواس، ع. س. (11 • (Y). الأظمة الجماعية لتعويض أضرار التلوث (تأمين المسئولية عن أخطار

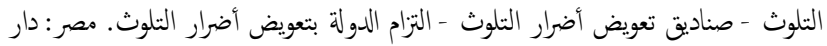
الجامعة الجديدة.

خويرة، ب. ا. (1 . (Y). الأثار المترتبة على عقد التأمين من المسؤولية المدنية. فلسطين: جامعة نجاح الوطنية.

الرحمن، ب. ع. (7 ( / ). المسؤولية المدنية عن الاضرار البيئية ودور التأمين. الجزائر: جامعة ابو بكر بلقليد.

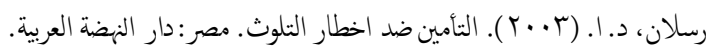

الزقرد، د. س. (1991). تعويض الاضرار الناشئة عن جرائم الارهاب. مصر: دار الجامعة الجديدة.

الزقرد، د. س. (9 . . †). تعويض ضحايا مرض الايدز والتهاب الكبد الوبائي بسبب قّل دم ملوث. مصر:دار النهضة العربية للنشر والتوزيع.

سرور، د. م. (191V ). التأمين ضد الاخطار التكنولوجية. مصر: دار الفكر العربي. السلام، د. س (د، ت). مشكلة تعويض أضرار البيئية التكنولوجية. مصر:دار النهضة العربية. السنهوري، ع. ا. ( . . ( ). الوسيط في شرح القانون المدني، عقود الغرر. لبنان: منشورات حلبي الحقوقية.

قادة، ع. (T • (Y). المسؤولية المدنية عن الاضرار البيئية. مصر: دار الجامعة الجديد.

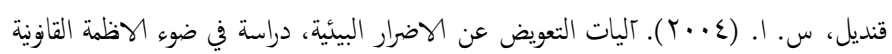
والاثفاقيات الدولية. مصر: دار الجامعة الجديدة.

الكعبي، م.أ. (·r · (Y). المسؤولية المدنية عن اضرار الكوارث الطبيعية. مصر:دار التعليم الجامعي. الكيلاني، م. (Y (Y). الموسوعة التجارية والمصرفية، المجلد السادس، عقود التّمين من الناحية

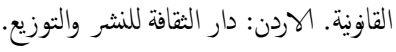
محمد صالح، د. (9.9 . . ). القانون التجاري. مصر:شركة العاتك لصناعة كناب. محمود، ع. ا. (ع 199 ). المسؤولية عن الاضرار الناتجة عن تلوث البيئة. مصر: جامعة القاهرة.

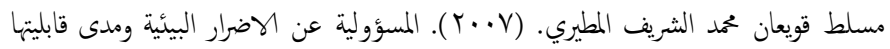
لمتأمين. مصر: جامعة الانسكندرية.

قانون البيئة المصري رق ع لسنة ع199 القانون المدني العراقي رقٌ (•ع) لسنة 1901.

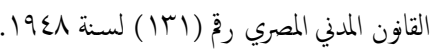

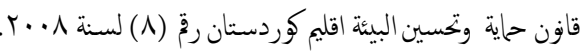

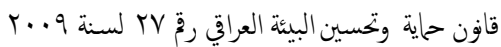

Spaeter ،S. (2004). L'incidence des régimes de responsabilité environnementale sur les comportements de prévention et d'assurance des firmes. Revue économique ،vol55(n2) 229. r. أن الثأمين من أخطار الثنلوث هو نوع من أنواع التأمين من المسؤولية، والذي

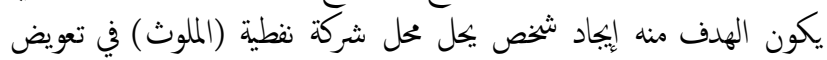

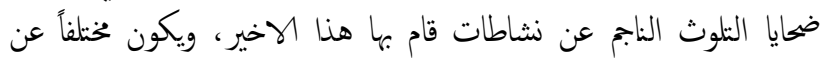

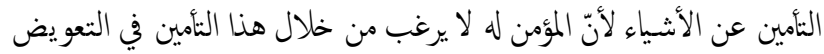

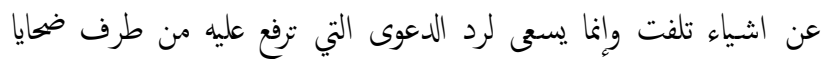

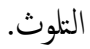

r. إذاكن الخطر غير موجود يكون عقد التأمين باطلاً لتخلف ركن المحل، و لأيمكن

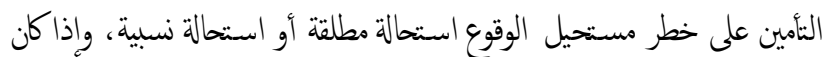

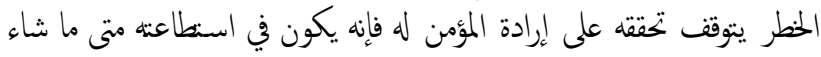

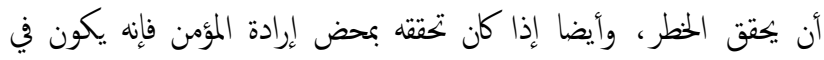

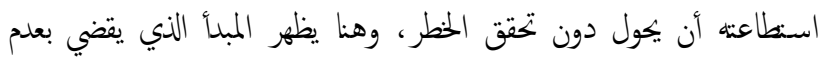

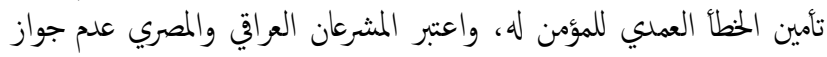
التامين على الخطأ العمدي من النظام العام.

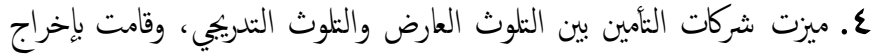

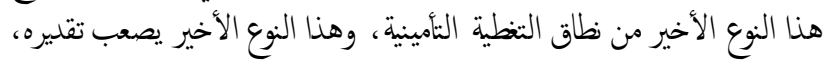

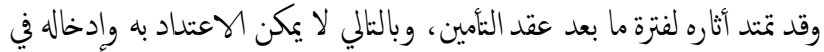

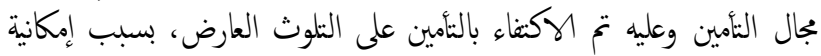
تحديد الصفة الفجائية فيه.

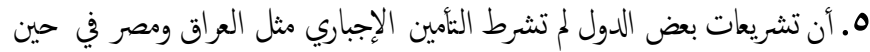
أن الاتجاهات العامة في التشريعات الحديثة هي في فرض التأمين الاجباري.

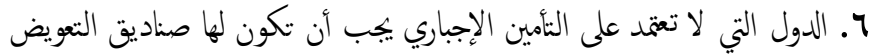

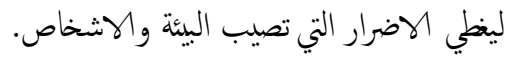

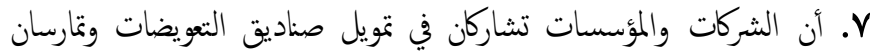

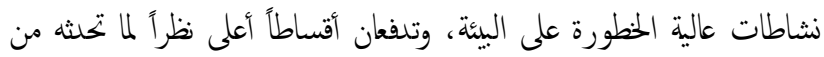

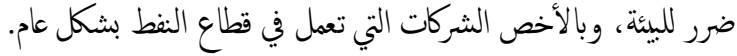

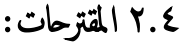

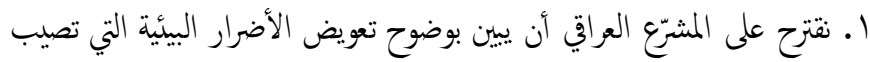
الاشخاص أو تصيب البيئة نفسا إلا في حالات الكوارث البيئية حيث يتدخل الصندوق. في غير ذلك، يهدف الصندوق إلى منع وقوع التلوث البئي ونشر

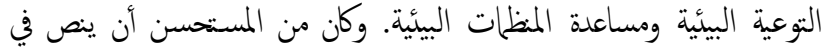

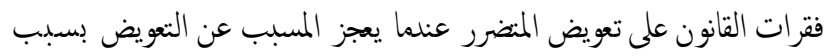

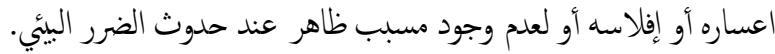
r. نقتزح على الجهة التنفيذية في إقليم كوردستان ودولة العراق آن يتم تفعيل

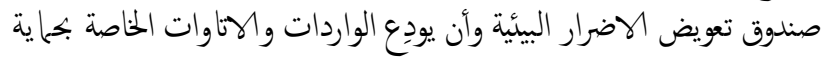
البيئة والغرامات التي تؤخذ من الثركات والجهات الملوثة للبئة إلى هنا الصندوق.

\section{ه. قامُمة المراجع}

إسماعيل، أ. م. (1) • ( ) "التغطية التأمينية من مخاطر الأضرار البيئية." المؤتمر البيئة والقانون. مصر: جامعة طنطا.

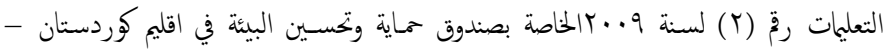
العراق. 